Received 00th January 20xx Accepted 00th January 20xx DOI: $10.1039 / x 0 x x 00000 x$

\title{
Room Temperature Production of Graphene Oxide with Thermally- labile Oxygen Functional Groups for Improved Lithium Ion Batteries Fabrication and Performance
}

\author{
Jiadong Qin', Yubai Zhang ${ }^{+}$, Sean E. Lowe, Lixue Jiang, Han Yeu Ling, Ge Shi, Porun Liu, Shanqing \\ Zhang, Yu Lin Zhong*, Huijun Zhao* \\ Graphene oxide (GO) has drawn intense research interest over the past decade, contributing to remarkable progress in its \\ relevant applications. The chemical production of $\mathrm{GO}$, however, is challenged by destructive and slowly-propagating \\ oxidation, especially for large flake graphite. Herein, we reported a simple but effective method to produce well-oxidized \\ and less defective $\mathrm{GO}$ by chemically oxidizing commercially-available expandable graphite at room temperature $\left(25^{\circ} \mathrm{C}\right)$. \\ Compared to natural graphite with similar flake sizes, expandable graphite afforded faster complete oxidation under the \\ same oxidizing conditions. In addition, chemical oxidation at room temperature, relative to higher temperatures (35 and 45 \\ ${ }^{\circ} \mathrm{C}$ ), resulted in reduced defect concentration in $\mathrm{GO}$. Furthermore, the $\mathrm{GO}$ derived from the oxidation of expandable graphite \\ at room temperature exhibited superior electrical conductivity after mild thermal treatment at $150{ }^{\circ} \mathrm{C}$. Considering the \\ energy-saving in both the GO synthesis and reduction, the low temperature GO conversion process can be easily integrated \\ into many other electroconductive applications. As a proof of concept, we achieved a good $\mathrm{LiFePO}_{4}$ (without carbon-coating) \\ cathode formulation with our GO, contributing as a 2D binder (before annealing), and obtained a conductive cathode with \\ improved capacity and high rate performance after mild thermal annealing at $150^{\circ} \mathrm{C}$.
}

\section{Introduction}

Graphene and graphene-based materials are appealing to a myriad of applications, such as energy storage devices, ${ }^{1}$ electrocatalysis, ${ }^{2}$ and sensors. ${ }^{3}$ As one of the most important precursor to graphene materials, graphene oxide (GO) has been widely adopted in both lab-scale research and industrial production due to its excellent chemical processability and production scalability. ${ }^{4-6}$ Currently, the exfoliation of chemically oxidized graphite, produced via the modified Hummers method, to GO is the most popular GO synthesis method owing to its rich oxygen functional groups and quantitative yield of single-layer GO. ${ }^{7-15}$ However, the harsh conditions in the strong chemical oxidation will incur permanent defects, uncontrollable functionality and even fragmentation in the resultant GO. ${ }^{16-19}$ In addition, it is limited by the slow diffusion of oxidizing agents. ${ }^{20}$ Particularly for large flake graphite, oxidants will have difficulty reaching the core region of the graphite, resulting in nonuniform oxidation and cracking in the GO sheets. ${ }^{18}$ Therefore, much effort has been put into optimizing the chemical oxidation method, mainly focusing on the starting materials and oxidation conditions.

Centre for Clean Environment and Energy, School of Environment and Science, Griffith University Gold Coast Campus, Queensland 4222, Australia. *Email: y.zhong@griffith.edu.au, h.zhao@griffith.edu.au

† These authors contribute equally to this work.

+ Electronic Supplementary Information (ESI) available: Table S1-S4 and Figure S1S6. See DOI: $10.1039 / x 0 x x 00000 x$
To facilitate oxidation and exfoliation, one strategy is to preintercalate the graphite to form graphite intercalation compound (GIC) with increased interlayer spacing and weakened Van der Vaal interaction between graphite layers. ${ }^{21}$ In 1999, Kovtyukhova et al. demonstrated a two-step oxidation method in which natural graphite was pre-intercalated in concentrated $\mathrm{H}_{2} \mathrm{SO}_{4}, \mathrm{~K}_{2} \mathrm{~S}_{2} \mathrm{O}_{8}$ and $\mathrm{P}_{2} \mathrm{O}_{5}$, followed by the Hummers method. ${ }^{22}$ It was later found that the pre-treated graphite was more susceptible to oxidation and exfoliation into monolayer GO sheets and hence the protocol has been adopted in many more recent works. ${ }^{9,} 23$ This two-step oxidation route, however, presents challenges for the mass production of GO due to the time-consuming pre-treatment, which involves the wetting and drying of graphite. Another strategy is to employ expanded graphite, which features a worm-like structure, as the starting material to produce GO. The expanded graphite is typically achieved by the thermal expansion of graphite bisulfate, a type of graphite intercalation compounds (GIC), also known as expandable graphite. In 2009, Luo et al. synthesized highquality GO sheets using microwave-expanded graphite, where the interlayer galleries were dramatically expanded, as the starting material. ${ }^{24}$ Since then, several research groups have shown that expanded graphite is a more suitable graphite source for preparing large-area GO sheets than natural graphite. ${ }^{25-27}$ Recently, Lu et al. proposed a new type of chemically expandable graphite in which the expansion was initiated by the oxygen evolution from the chemical reaction of $\mathrm{CrO}_{3}$ graphite intercalant with $\mathrm{H}_{2} \mathrm{O}_{2} \cdot{ }^{28}$ Though the expanded graphite was very readily oxidized even under mild agitation- 
free condition, this novel method is challenged by the complicated procedures and the introduction of toxic $\mathrm{Cr}^{6+}$ ions. ${ }^{28}$

With regards to oxidation conditions, Eigler et al. kept the oxidation at temperature below $10{ }^{\circ} \mathrm{C}$ to yield highly intact $\mathrm{GO}$ with preserved the structural integrity. ${ }^{29,} 30$ However, this lowtemperature method has its limitations, namely the timeconsuming procedures and low GO yield. Apart from lowering the reaction temperature, it has been reported that the addition of a small amount of water to the chemical oxidation system not only promoted oxidation but also reduced the defects in GO. ${ }^{31,} 32$

Typically, the reduction of GO, by which its electrical conductivity can be restored, is required for the majority of applications such as lithium ion batteries (LIBs) and supercapacitors. ${ }^{9}, 33$ The common reduction methods involve chemical reduction (such as hydrazine and hydroiodic acid) ${ }^{34,35}$ and thermal treatment at high temperature ${ }^{19,36}$. Zhu and coworkers reduced $\mathrm{GO}$ dispersion in an anhydrous organic solvent, propylene carbonate, by heating at only $150{ }^{\circ} \mathrm{C}$, but for 12 hours. ${ }^{37}$ The mild thermal reduction, without the need for reducing agent or high temperature treatment, will be very useful for the incorporation of reduced GO (rGO) into a wide range of electroconductive applications. For example, it has been shown that $\mathrm{rGO}$ worked well as the conductive additive in lithium ion batteries (LIBS) electrodes, effectively improving charge transport due to its good conductivity, high surface area and flexible two dimensional structure.6, 36, 38 The low temperature thermal treatment could help to simplify the fabrication of LIBs by allowing GO to be blended with electrode materials and then reduced in situ. Due to its good dispersibility in multiple solvents, unreduced $\mathrm{GO}$ can be homogeneously mixed with $\mathrm{LiFePO}_{4}$ particles. This can enable the uniform coating/wrapping of $\mathrm{GO}$ around the particles, minimizing the unwanted polarization in LIBs. ${ }^{39}$

In this work, we report a mild GO production approach from large-sized expandable graphite (graphite bisulfate, a type of GIC) flakes via the modified Hummers method, resulting in more thorough oxidation than natural graphite under the same conditions. We optimized the oxidation temperature and time for this GIC-based GO synthesis and found that well-oxidized GO was obtained at an oxidation temperature of $25{ }^{\circ} \mathrm{C}$ for $8 \mathrm{~h}$ (denoted as $\mathrm{GO}_{\mathrm{GIC}}-25-8 \mathrm{~h}$ ). This $\mathrm{GO}$, synthesized at room temperature, was found to be less defective and more prone to deoxygenation during low temperature annealing $\left(150{ }^{\circ} \mathrm{C}\right)$. After $150{ }^{\circ} \mathrm{C}$ thermal reduction in air, $\mathrm{GO}_{\mathrm{GIC}}-25-8 \mathrm{~h}$ restored more $\mathrm{sp}^{2}$ carbon atoms and was also more conductive than other GO oxidized at higher temperature, which indicates the facile removal of oxygenated functional groups. Our work also demonstrates that the $\mathrm{GO}_{\mathrm{GIC}}-25-8 \mathrm{~h}$ was able to blend well in typical $\mathrm{LiFePO}_{4}$ (without carbon-coating) cathode formulation and helped to deliver pronounced improvement in the capacity and high rate performance of LIBs after mild thermal annealing process.

\section{Experimental}

\section{Materials}

The expandable graphite used in the experiments was received from Asbury Graphite Mills (Grade 1721). The natural flake graphite was from Sigma-Aldrich (Product No. 332461). Both graphite sources were carefully sieved to control the flake sizes between 200 and $300 \mu \mathrm{m}$ for the $\mathrm{GO}$ synthesis reactions. $\mathrm{KMnO}_{4}(99.0 \%)$, concentrated $\mathrm{H}_{2} \mathrm{SO}_{4}$ (98\%), $\mathrm{H}_{2} \mathrm{O}_{2}$ aqueous solution $(30 \% \mathrm{w} / \mathrm{w})$ and hydrochloric acid (32 wt.\%) were purchased from Chem-supply. Deionized water was used in all experimental procedures, including synthesis reaction and purification.

\section{Synthesis of graphene oxide from expandable graphite (GIC)} and natural graphite (NG) under different conditions.

The GO synthesis procedures were based on a modified Hummers method as illustrated in Figure 1.14, 40 The flake graphite $(1 \mathrm{~g})$ was mixed with concentrated $\mathrm{H}_{2} \mathrm{SO}_{4}(50 \mathrm{~mL})$ in a $500 \mathrm{~mL}$ three-neck flask which was placed in the ice bath with mechanical stirring at $120 \mathrm{rpm}$. After cooling to below $10{ }^{\circ} \mathrm{C}$, $\mathrm{KMnO}_{4}(3 \mathrm{~g})$ was slowly added to the mixture and the mixture kept in the ice bath for $1 \mathrm{~h}$. Then, removing the ice bath, the temperature was elevated to the designated temperature $(25$, 35 and $45{ }^{\circ} \mathrm{C}$ ) at which point the mixture was stirred for a specified period ( 4,6 and 8 h.). After this stage, the water bath was replaced by an ice bath to minimize the temperature rise in the following steps. $150 \mathrm{~mL}$ of chilled water was slowly dropped into the mixture via a peristaltic pump over a period of $90 \mathrm{~min}$ and then the reaction system was kept in the ice bath for another $30 \mathrm{~min}$. At the end of reaction, $\mathrm{H}_{2} \mathrm{O}_{2}$ was added to the mixture dropwise to react away the residual $\mathrm{KMnO}_{4}$ until the color of the resulting product no longer changed. To remove metal ions, $300 \mathrm{~mL}$ diluted aqueous $\mathrm{HCl}$ solution (1:9) was added to the product. The product was allowed to settle overnight. The resulting sediment was washed with water and centrifuged at $13000 \mathrm{rpm}$ for $15 \mathrm{~min}$ repeatedly until the $\mathrm{pH}$ of supernatant stabilized at $\sim 4$. Finally, the resultant sediment was resuspended in deionized water to a total volume of $200 \mathrm{~mL}$. The GO products made from expandable graphite and natural graphite are denoted as $\mathrm{GO}_{\mathrm{GI}}$ and $\mathrm{GO}_{\mathrm{NG}}$, respectively, and the oxidation temperatures and reaction time are abbreviated as, for example, $\mathrm{GO}_{\mathrm{GIC}}-25-4 \mathrm{~h}$ (the product derived from the $\mathrm{GIC}$, with a $25^{\circ} \mathrm{C}, 4 \mathrm{~h}$ reaction time).

\section{Yield Calculation}

$5 \mathrm{~mL}$ of the purified $\mathrm{GO}$ aqueous dispersion was cast into a dense film on a nylon membrane via vacuum filtration and then dried in a $60{ }^{\circ} \mathrm{C}$ oven overnight. The polymer membrane was then gently peeled off and the weight of the freestanding GO film which was used to calculate the concentration of $\mathrm{GO}\left(\mathrm{C}_{\mathrm{GO}}\right.$, $\mathrm{mg} / \mathrm{mL}$ ). The yield of $\mathrm{GO}$ was calculated by the equation $\mathrm{Y}_{\mathrm{GO}}=\mathrm{C}_{\mathrm{GO}} \times \mathrm{V}_{\mathrm{GO}} / \mathrm{m}_{\mathrm{Gr}}$ where $\mathrm{V}_{\mathrm{GO}}$ is the total volume of $\mathrm{GO}$ solution after purification $(200 \mathrm{~mL})$ and $\mathrm{m}_{\mathrm{Gr}}$ is the mass of starting graphite. Specially, in the case of $\mathrm{GO}_{\mathrm{GIC}}, \mathrm{m}_{\mathrm{Gr}}$ only refers to the graphite component, excluding the intercalating compounds.

\section{Characterizations}




\section{Sieved graphite}

1. Natural Graphite (NG)

2. Expandable Graphite (GIC)

\section{Characterizations \& Applications}

\section{- Extent of oxidation}

- Feasibility of thermal reduction at low temperature $\left(150^{\circ} \mathrm{C}\right)$

- Electrochemical performance in lithium ion batteries

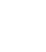

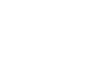

\section{Stir the mixture in} the ice bath for $1 \mathrm{~h}$.

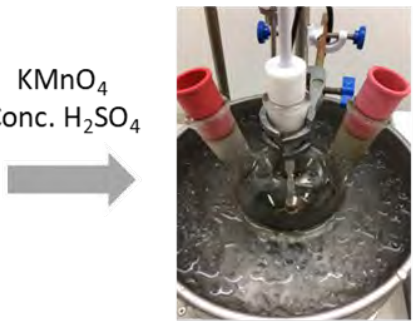

$\mathrm{KMnO}_{4}$ Conc. $\mathrm{H}_{2} \mathrm{SO}_{4}$ 
voltammetry (CV) measurement was performed on a $\mathrm{CHI} 660 \mathrm{D}$ electrochemical workstation with a scan rate of $0.1 \mathrm{mV} \mathrm{s}^{-1}$.
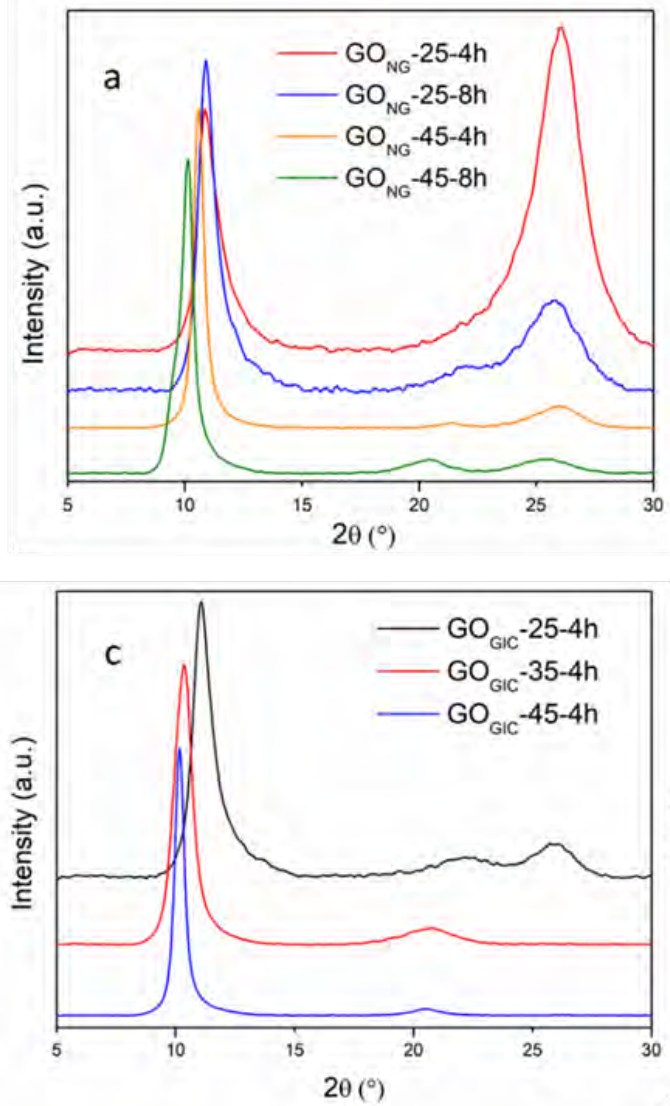

to the left (from $10.6^{\circ}$ to $10.1^{\circ}$ ) when the oxidation time is doubled at $45{ }^{\circ} \mathrm{C}$, which is associated with the interlayer expansion and the
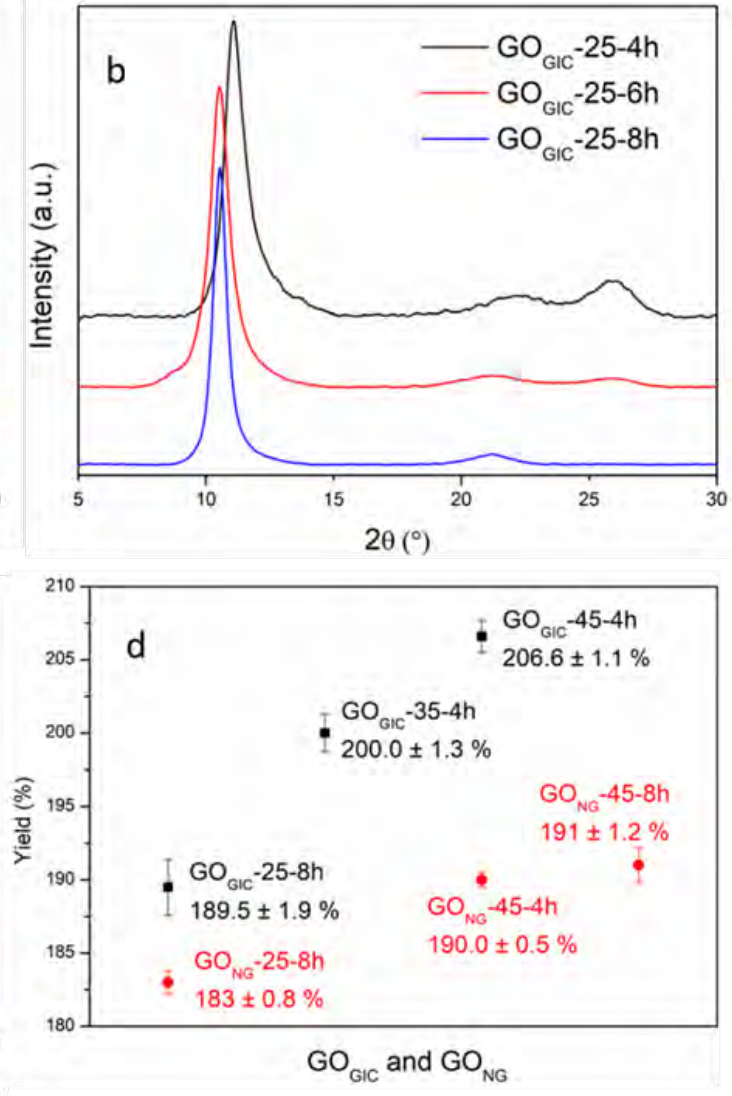

Figure 2. XRD patterns for (a) $\mathrm{GO}_{\mathrm{NG}}$ from different oxidation conditions, (b) $\mathrm{GO}_{\mathrm{GIC}}$ oxidized at $25{ }^{\circ} \mathrm{C}$ for different times. (c) $\mathrm{GO}_{\mathrm{GIC}}$ oxidized at different temperature for $4 \mathrm{~h}$, and (d) Yield comparison between $\mathrm{GO}_{\mathrm{NG}}$ and $\mathrm{GO}_{\mathrm{GIC}}$.

\section{Results and discussions}

\section{The effects of graphite sources.}

GO samples were prepared by oxidizing expandable graphite (GIC) and natural graphite (NG), respectively, at different temperatures $\left(25,35\right.$ and $\left.45^{\circ} \mathrm{C}\right)$ for varying time $(4,6$ and $8 \mathrm{~h})$ with the modified Hummers method and the products were examined via $\mathrm{X}$-ray diffraction (XRD). The XRD patterns of the two starting materials (Figure S1) showed GIC had greater interlayer spacing between graphene layers (3.41 ̊̊ vs $3.36 \AA$ ) and lower crystallinity (broader graphitic peak) than NG. This suggests that GIC, with less compact structure, can provide more accessible paths for the diffusion of oxidizing agents than NG. Experimentally, this advantage of GIC can be demonstrated by the XRD results of $\mathrm{GO}_{\mathrm{NG}}$ and $\mathrm{GO}_{\mathrm{GIC}}$ (Figure 2a-c). Examining Figure $\mathbf{2 a}$, despite subjecting to prolonged oxidation time $(8 \mathrm{~h})$ and sufficiently high temperature $\left(45^{\circ} \mathrm{C}\right), \mathrm{GO}_{\mathrm{NG}}$ still showed a pronounced broad graphitic peaks at about $26^{\circ}$ (corresponding to the interlayer spacing $d \approx 3.4 \AA$ ), which is related to unoxidized graphite. ${ }^{41}, 42$ In addition, for $\mathrm{GO}_{\mathrm{NG}}-25-4 \mathrm{~h}$ and $\mathrm{GO}_{\mathrm{NG}}-25-8 \mathrm{~h}$, the position of the sharp low-angle peak, also known as GO peak, did not change and was about $10.9^{\circ}(\mathrm{d}=8.1 \AA)$. This suggests that the interlayer distance between $\mathrm{GO}$ sheets did not change with the oxidation time at $25^{\circ} \mathrm{C} .{ }^{41}$ In contrast, there was a shift in the $\mathrm{GO}$ peak oxidation degree of GO..$^{15}$

As evident in Figure $\mathbf{2 b}$, it was easier to oxidize GIC at $25^{\circ} \mathrm{C}$. The graphitic peak was much weaker in $\mathrm{GO}_{\mathrm{GIC}}-25-4 \mathrm{~h}$ (relative to the product derived from NG using the same oxidation conditions), and the graphitic peak disappeared after prolonging the oxidation time to $8 \mathrm{~h}$. Meanwhile, the left shift in the GO peak (from $11.1^{\circ}$ to $10.5^{\circ}$ ) reflected the expansion in interlayer spacing (from $8.0 \AA$ to $8.4 \AA$ ) and hence the slight increase in the degree of oxidation with reaction time at $25^{\circ} \mathrm{C}$. The GIC can also be completely transformed into GO after $4 \mathrm{~h}$ of oxidation at higher temperatures of $35{ }^{\circ} \mathrm{C}$ and $45{ }^{\circ} \mathrm{C}$, evidenced by the absence of the graphitic peaks in Figure $\mathbf{2 c}$. Therefore, using GIC as the starting material allows for milder reaction condition and more effective oxidation. Note that the small and broad peaks at around $21^{\circ}$ in the XRD patterns can be attributed to the randomly packed single graphene layers. ${ }^{43}$

To measure the graphite content in GIC, the material was heated to $1000{ }^{\circ} \mathrm{C}$ under the argon atmosphere in order to gasify the intercalants, water and remove any oxygen functionalities. ${ }^{24,44}$ The TGA curves (Figure S2) showed 76 wt. \% of material remained in GIC, attributed to the graphite component of $\mathrm{GIC},{ }^{45}$ while NG did not lose any mass after heated to $1000^{\circ} \mathrm{C}$. Therefore, the yield of $\mathrm{GO}_{\mathrm{GIC}}$ can be calculated with respect to the starting graphitic material and compared with that of $\mathrm{GO}_{\mathrm{NG}}$, as illustrated in Figure $\mathbf{2 d}$. In general, the $\mathrm{GO}_{\mathrm{GI}}$ had higher yield than $\mathrm{GO}_{\mathrm{NG}}$ under the same reaction 


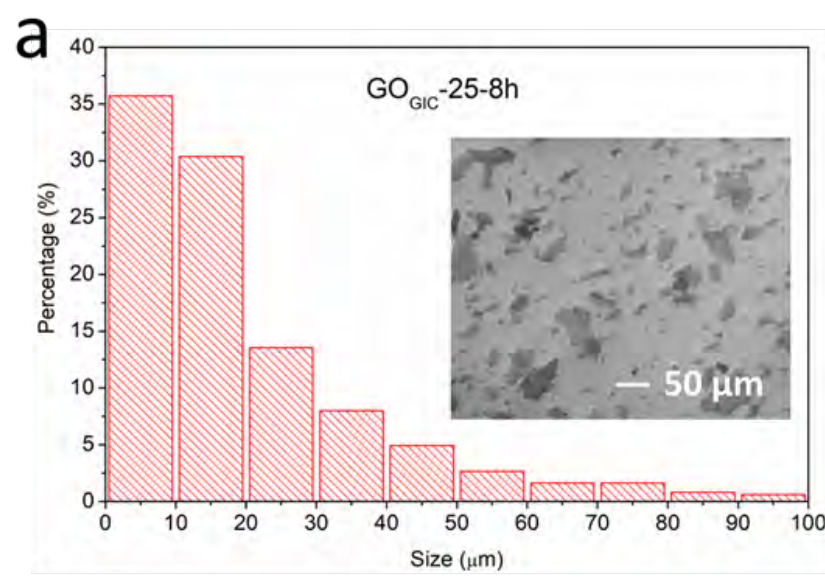

b
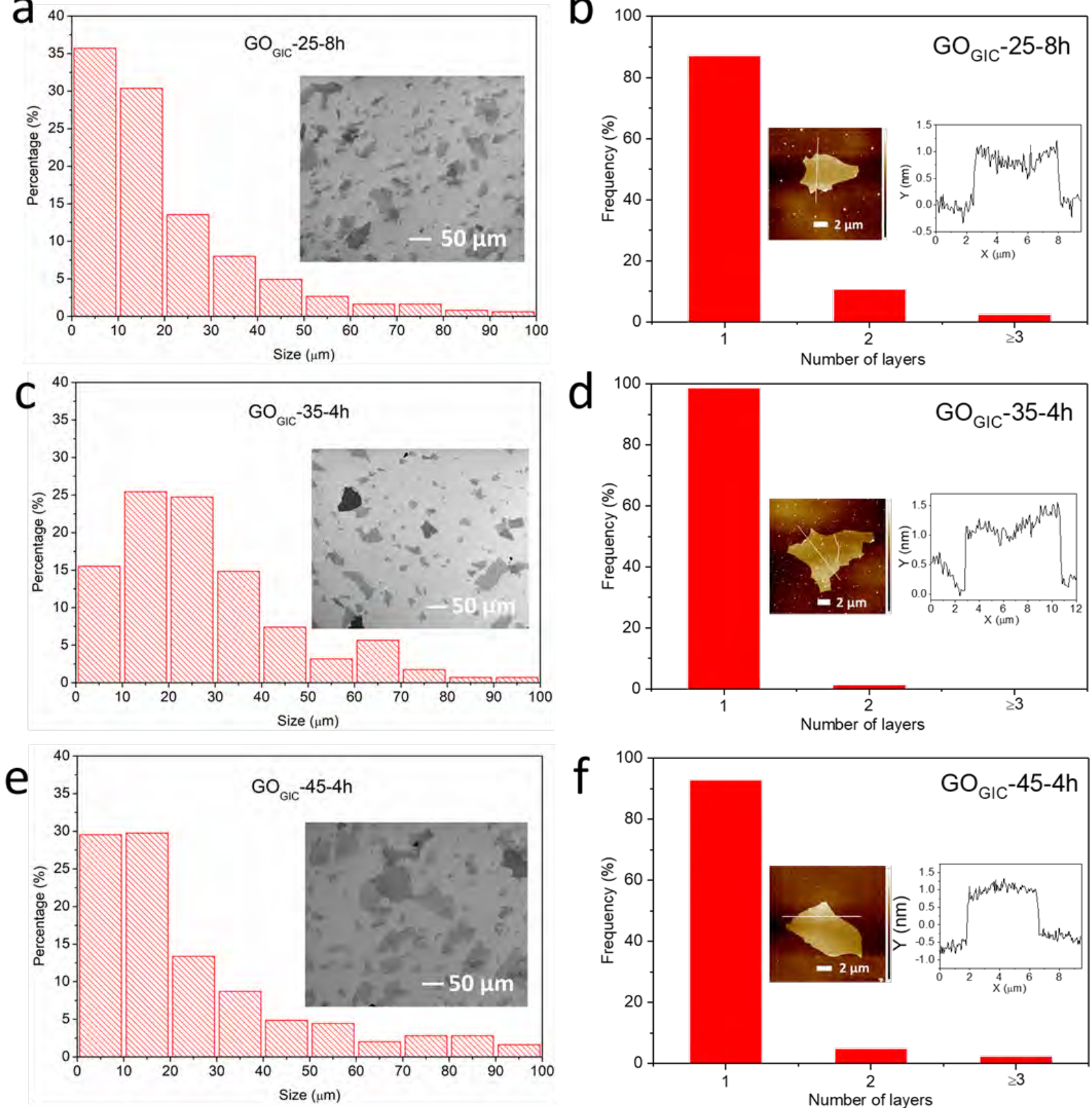

Figure 3. Morphological characterizations of fully oxidized $\mathrm{GO}_{\mathrm{GIC}}$ samples. (a), (c) and (e): SEM images of $\mathrm{GO}_{\mathrm{GIC}}$ sheets coated onto the $\mathrm{Si}$ wafers and the corresponding flake size distributions. (b), (d) and (f): Frequency distributions of the number of layers in the GO samples (statistics were based on more than $80 \mathrm{GO}$ flakes). The insets are the AFM images of the individual $\mathrm{GO}$ sheets and their corresponding height profiles.

conditions and the gap became even wider at higher temperatures due to the greater extend of oxidation in GIC. In comparison to other reported room or low temperature synthesis, our yield of $190 \%$ for $\mathrm{GO}_{\mathrm{GIC}}-25-8 \mathrm{~h}$ is one of the highest so far. ${ }^{29,32,46}$

\section{Morphological characterizations of fully oxidized $\mathrm{GO}_{\mathrm{GIC}}$.}

In the subsequent work, only the fully oxidized samples $\left(\mathrm{GO}_{\mathrm{GIC}}-25-\right.$ $8 \mathrm{~h}, \mathrm{GO}_{\mathrm{GIC}}-35-4 \mathrm{~h}$ and $\mathrm{GO}_{\mathrm{GIC}}-45-4 \mathrm{~h}$ ) were further characterized and compared. The lateral size distributions of $\mathrm{GO}$ sheets were obtained statistically from SEM images (Figure 3a, $\mathrm{c}$ and e). For $\mathrm{GO}_{\mathrm{GIC}}-25-8 \mathrm{~h}$, $\mathrm{GO}_{\mathrm{GIC}}-35-4 \mathrm{~h}$ and $\mathrm{GO}_{\mathrm{GIC}}-45-4 \mathrm{~h}$, the average sizes were $20.1 \pm 17.9$,
$27.3 \pm 18.6$ and $24.5 \pm 22.0$ (mean \pm standard deviation) $\mu \mathrm{m}$, respectively. It is noteworthy that $\mathrm{GO}_{\mathrm{GIC}}-25-8 \mathrm{~h}$ had the smallest average lateral size as well as the highest content of $<20 \mu \mathrm{m}$ flakes. Although the oxidation proceeded at lower temperature, $\mathrm{GO}_{\mathrm{GIC}}-25$ $8 \mathrm{~h}$ was also subjected to $8 \mathrm{~h}$ of mechanical stirring which likely led to the mechanical cleavage of the GO sheets. ${ }^{18,} 47$ Examining the thickness distributions of $\mathrm{GO}_{\mathrm{GIC}}$ sheets from AFM images (Figure $\mathbf{3 b}$, d and $\mathbf{f}$ ), the majority of $\mathrm{GO}_{\mathrm{GIC}}$ sheets were successfully exfoliated down to single layer. The single-layer sheets were between 1.0 and $1.5 \mathrm{~nm}$ thick, consistent with previous literature reports. ${ }^{15,} 48$ 

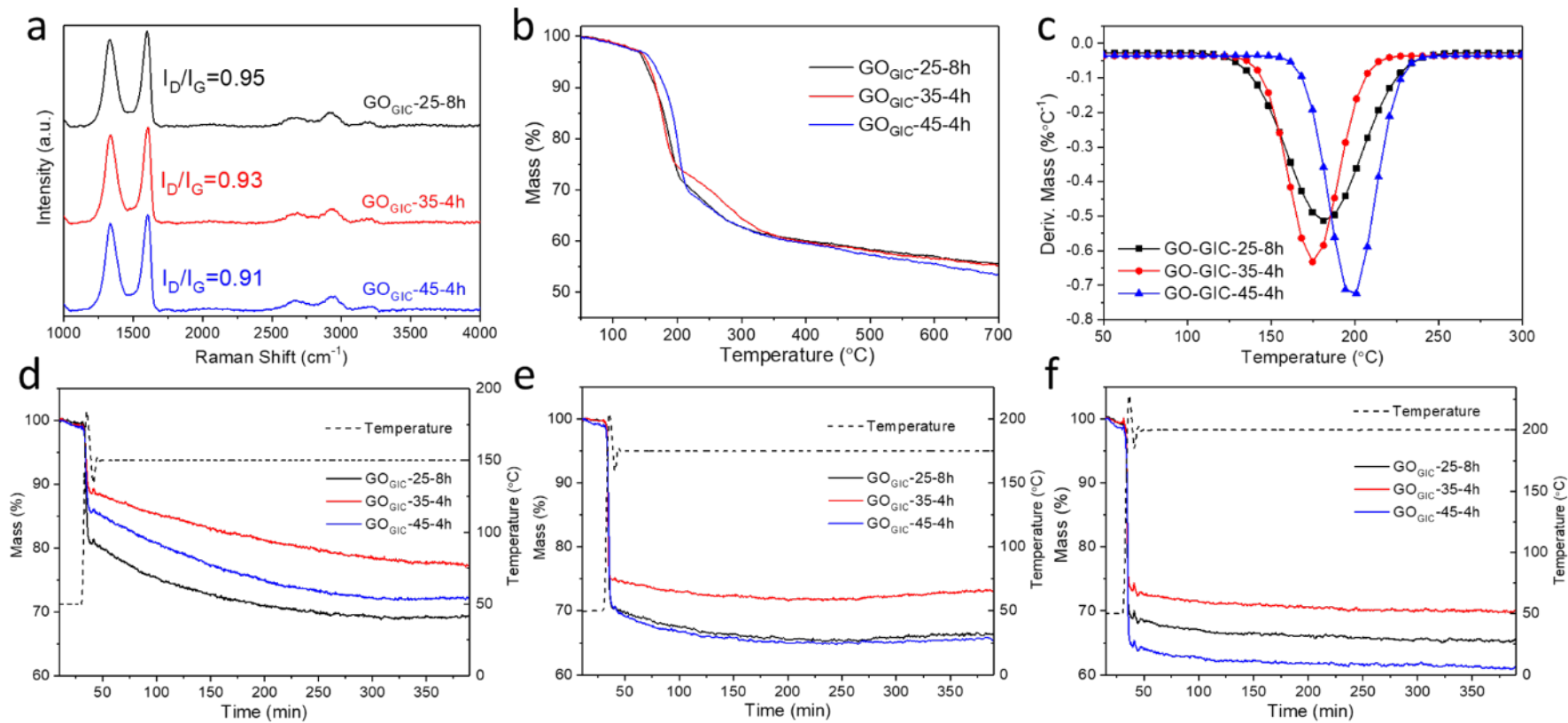

Figure 4. Chemical properties of different $\mathrm{GO}_{\mathrm{GIC}}$ samples. (a) Raman spectra of $\mathrm{GO}_{\mathrm{GIC}}$ flakes. (b) TGA curves for heating $\mathrm{GO}$ in argon at a 5 $\mathrm{K} /$ min heating rate. (c) The corresponding first derivative of the TGA curves in the temperature range $50 \sim 300^{\circ} \mathrm{C}$. (d-f) TGA curves for thermal annealing of $\mathrm{GO}_{\mathrm{GIC}}$ at 150,175 and $200{ }^{\circ} \mathrm{C}$ under $20 \%$ oxygen/80 \% argon atmosphere.

\section{Chemical characterizations of fully oxidized $\mathrm{GO}_{\mathrm{GIC}}$ before and after} thermal reduction.

To further investigate the effects of different oxidation conditions, Raman spectroscopy (Figure S3) was used to discriminate different carbon atoms, typically featuring $D\left(\sim 1350 \mathrm{~cm}^{-1}\right), G\left(\sim 1585 \mathrm{~cm}^{-1}\right)$ and 2D $\left(\sim 2700 \mathrm{~cm}^{-1}\right)$ peaks. The $D$ peak is attributed to the breathing modes of six-atom carbon rings in proximity to defect areas. The 2D peak is the overtone of the $D$ peak, while the $G$ peak is related to the motion of $\mathrm{sp}^{2}$ carbon atoms. ${ }^{49}$ The ratio of the defect-activated $\mathrm{D}$ peak to $G$ peak is an important parameter to reveal the defect density in GO. According to Ferrari and Robertson, 50 for graphene materials, $I_{D} / I_{G}$ initially increases with defect density at low defect concentration (stage 1) and subsequently declines after reaching a certain defect concentration (stage 2). From the Raman spectra of various $\mathrm{GO}_{\mathrm{GIC}}$ in Figure $\mathbf{S 3}$, the value of $\mathrm{I}_{\mathrm{D}} / \mathrm{I}_{\mathrm{G}}$ tended to decrease with longer oxidation time or higher temperature. Therefore, all $\mathrm{GO}_{\mathrm{GIC}}$ samples were likely to be in the stage 2 state because more defects will be introduced to the honeycomb lattice in graphene layers as the proceeding chemical oxidation or the elevating temperature. ${ }^{18,} 29$ Comparing the fully oxidized $\mathrm{GO}_{\mathrm{GIC}}$ samples (Figure 4a), the defect density increased in the following sequence: $\mathrm{GO}_{\mathrm{GIC}}-25-8 \mathrm{~h}<\mathrm{GO}_{\mathrm{GIC}}-35$ $-4 \mathrm{~h}<\mathrm{GO}_{\mathrm{GIC}}-45-4 \mathrm{~h}$.

The weight change in $\mathrm{GO}_{\mathrm{GIC}}$ with increasing temperature was tracked using thermogravimetric analysis (TGA, Figure $4 b$ ), and it was found that the greatest weight loss was observed for $\mathrm{GO}_{\mathrm{GIC}}-45-4 \mathrm{~h}$. Only $53.6 \%$ of the material remained after heating to $700{ }^{\circ} \mathrm{C}$, which suggested it had the highest content of thermally labile oxygenated function groups. Moreover, the corresponding first derivative TGA curves (Figure 4c) were plotted to give insight into the peak decomposition temperature $\left(T_{d}\right)$ where $G O$ samples underwent the greatest rate of change in the weight. ${ }^{31,32}$ It was obvious that $\mathrm{GO}_{\mathrm{GIC}}$ 45-4h had a higher $\mathrm{T}_{\mathrm{d}}\left(198{ }^{\circ} \mathrm{C}\right)$ than $\mathrm{GO}_{\mathrm{GIC}}-25-8 \mathrm{~h}\left(181^{\circ} \mathrm{C}\right)$ and $\mathrm{GO}_{\mathrm{GIC}^{-}}$
$35-4 \mathrm{~h}\left(175^{\circ} \mathrm{C}\right)$. In fact, the removal of oxygenated function groups from $\mathrm{GO}$ basal planes always accompanies the formation of various gases, including $\mathrm{CO}_{2}, \mathrm{CO}$ and $\mathrm{H}_{2} \mathrm{O} .{ }^{51}$ Because the gasification process must overcome the interlayer interactions, it can be inferred that $\mathrm{GO}_{\mathrm{GIC}}-45-4 \mathrm{~h}$ with the highest $\mathrm{T}_{\mathrm{d}}$ had the greatest amount of carboxyl group with strong hydrogen bonding ability. ${ }^{31}$

Mild thermal annealing in ambient air is a simple and effective route to deoxygenate $\mathrm{GO} .{ }^{52} \mathrm{By}$ comparing the weight changes for $\mathrm{GO}_{\mathrm{GIC}}$ annealed at different constant temperatures (Figure $4 \mathrm{~d}-\mathrm{f}$ ), $\mathrm{GO}_{\mathrm{GIC}}-25$ $8 \mathrm{~h}$ saw the most weight loss at $150{ }^{\circ} \mathrm{C}$, relative to other conditions, while $\mathrm{GO}_{\mathrm{GIC}}-45-4 \mathrm{~h}$ lost more weight at 175 and $200{ }^{\circ} \mathrm{C}$, implying deoxygenation of $\mathrm{GO}_{\mathrm{GIC}}-25-8 \mathrm{~h}$ occurred more readily at lower temperature than $\mathrm{GO}_{\mathrm{GIC}}-45-4 \mathrm{~h}$. As shown in Table S1, the percentage of residual mass changed from $69 \%$ to $65 \%$ in $\mathrm{GO}_{\mathrm{GIC}}-25-8 \mathrm{~h}$ as raising the annealing temperature from 150 to $200{ }^{\circ} \mathrm{C}$. This change was much smaller than that in $\mathrm{GO}_{\mathrm{GIC}}-35-4 \mathrm{~h}$ or $\mathrm{GO}_{\mathrm{GIC}}-45-4 \mathrm{~h}$, also indicative of the easier deoxygenation of $\mathrm{GO}_{\mathrm{GIC}}-25-8 \mathrm{~h}$ at $150{ }^{\circ} \mathrm{C}$. In addition, $\mathrm{GO}_{\mathrm{GIC}}-35-4 \mathrm{~h}$ always experienced the lowest mass reduction, regardless of the annealing temperature, suggesting that $\mathrm{GO}_{\mathrm{GIC}}-35$ $4 \mathrm{~h}$ was less oxidized than $\mathrm{GO}_{\mathrm{GIC}}-25-8 \mathrm{~h}$ and $\mathrm{GO}_{\mathrm{GIC}}-45-4 \mathrm{~h}$. This was consistent with the XPS scan which showed $\mathrm{GO}_{\mathrm{GIC}}-35-4 \mathrm{~h}$ had the highest $\mathrm{C} / \mathrm{O}$ ratio from XPS survey scan (Figure S4). In addition, during the $150{ }^{\circ} \mathrm{C}$ thermal treatment, the residual weights of $\mathrm{GO}_{\mathrm{GIC}}$ $25-8 \mathrm{~h}$ and $\mathrm{GO}_{\mathrm{GIC}}-45-4 \mathrm{~h}$ became stable after $5 \mathrm{~h}(\mathrm{~d})$, corresponding to the completion of thermal reduction.

The XPS C 1s peak (Figure 5) can be deconvoluted into five components, including the $\mathrm{C}=\mathrm{C} / \mathrm{C}-\mathrm{C}$ in aromatic rings $(284.6 \mathrm{eV}), \mathrm{C}-\mathrm{O}$ $(286.1 \mathrm{eV}), \mathrm{C}=\mathrm{O}(287.5 \mathrm{eV}), \mathrm{COOH}(289.0 \mathrm{eV})$ and $\pi-\pi^{*}$ satellite (290.6 $\mathrm{eV}),{ }^{53}$ and the fractions of these components in each sample are summarized in Table S2 and Table S3. Among the $\mathrm{GO}_{\mathrm{GIC}}$ samples (Figure 5a, c, e and Table S2), the highest fraction of $\mathrm{C}=\mathrm{C} / \mathrm{C}-\mathrm{C}$ was found in $\mathrm{GO}_{\mathrm{GIC}}-35-4 \mathrm{~h}(56.6 \%)$ and the lowest was in $\mathrm{GO}_{\mathrm{GIC}}-45-4 \mathrm{~h}$ 

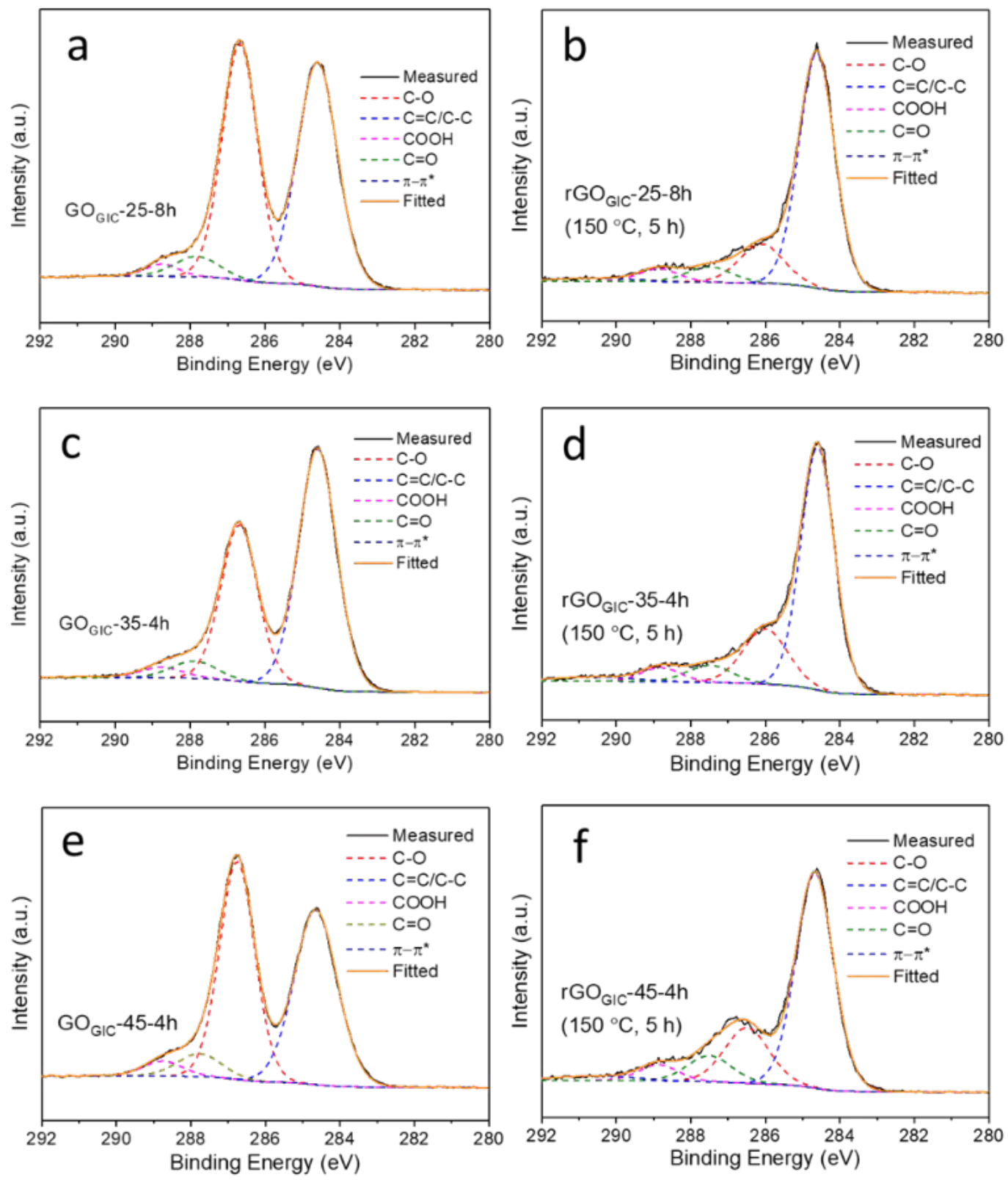

Figure 5. XPS C 1s spectra for the fully oxidized $\mathrm{GO}_{\mathrm{GIC}}$ samples, and the thermally reduced $\mathrm{GO}_{\mathrm{GIC}}$ samples which were annealed at $150{ }^{\circ} \mathrm{C}$ for $5 \mathrm{~h}$.

(45.1\%), which indicated $\mathrm{GO}_{\mathrm{GIC}}-35-4 \mathrm{~h}$ retained the most intact $\mathrm{sp}^{2}$ graphitic carbon while $\mathrm{GO}_{\mathrm{GIC}}-45-4 \mathrm{~h}$ was the most oxygenfunctionalized. $\mathrm{GO}_{\mathrm{GIC}}-25-8 \mathrm{~h}$ had the least amounts of $\mathrm{C}=\mathrm{O}$ and $\mathrm{COOH}$ (7.33\%) compared to $\mathrm{GO}_{\mathrm{GIC}}-35-4 \mathrm{~h}(7.62 \%)$ and $\mathrm{GO}_{\mathrm{GIC}}-45-4 \mathrm{~h}(9.53 \%)$. Due to the fact that carbonyl and carboxyl groups preferentially form at the edge of $\mathrm{GO}$ flakes or vacancy defects, $31,53,54 \mathrm{GO}_{\mathrm{GIC}}-25-8 \mathrm{~h}$ was the least defective among all fully oxidized $\mathrm{GO}_{\mathrm{GIC}}$ samples, consistent with results from the Raman spectra (Figure 4a) and the previous reports for GO produced at room temperature. ${ }^{32}$ Hence, roomtemperature oxidation can more effectively maintain the structural integrity of GO. Comparing the ATR-FTIR spectra for $\mathrm{GO}_{\mathrm{GIC}}$ (Figure S5), $\mathrm{GO}_{\mathrm{GIC}}-35-4 \mathrm{~h}$ had a weaker peak at $\sim 1722 \mathrm{~cm}^{-1}$ which suggested a lower concentration of carbonyl group, and this is also in agreement with the XPS results.
To investigate the changes in the functionalities after thermal reduction, the three reduced $\mathrm{GO}_{\mathrm{GIC}}$ samples, annealed at $150{ }^{\circ} \mathrm{C}$ for $5 \mathrm{~h}$, were examined by XPS (Figure $\mathbf{5 b}$, $\mathbf{d}$ and $\mathbf{f}$ ). As shown in Table S3, $\mathrm{rGO}_{\mathrm{GIC}}-25-8 \mathrm{~h}$ had the largest increase in the content of $\mathrm{sp}^{2}$ carbon with thermal treatment (from $48.18 \%$ to $72.56 \%$ ). This is indicative of its considerably easier deoxygenation and restoration of $\mathrm{sp}^{2}$ domains at $150^{\circ} \mathrm{C}$ thermal treatment, consistent with the isothermal TGA result (Figure 4d). Comparing the sheet resistances of the ultrathin $\mathrm{rGO}_{\mathrm{GIC}}$ films (all annealed at $150^{\circ} \mathrm{C}$ for $5 \mathrm{~h}$ ) measured using the four-point probe, $\mathrm{rGO}_{\mathrm{GIC}}-25-8 \mathrm{~h}(0.81 \pm 0.34 \mathrm{M} \Omega / \square$, mean \pm standard deviation) was more conductive than $\mathrm{rGO}_{\mathrm{GIC}}-35-4 \mathrm{~h}$ (1.13 \pm $0.14 \mathrm{M} \Omega / \square)$ and $\mathrm{rGO}_{\mathrm{GIC}}-45-4 \mathrm{~h}(8.48 \pm 0.73 \mathrm{M} \Omega / \square)$, which is related to the higher fraction of graphitic carbon in $\mathrm{rGO}_{\mathrm{GIC}}-25-8 \mathrm{~h}$. The $\pi-\pi^{*}$ satellite peak became more pronounced after thermal reduction of 

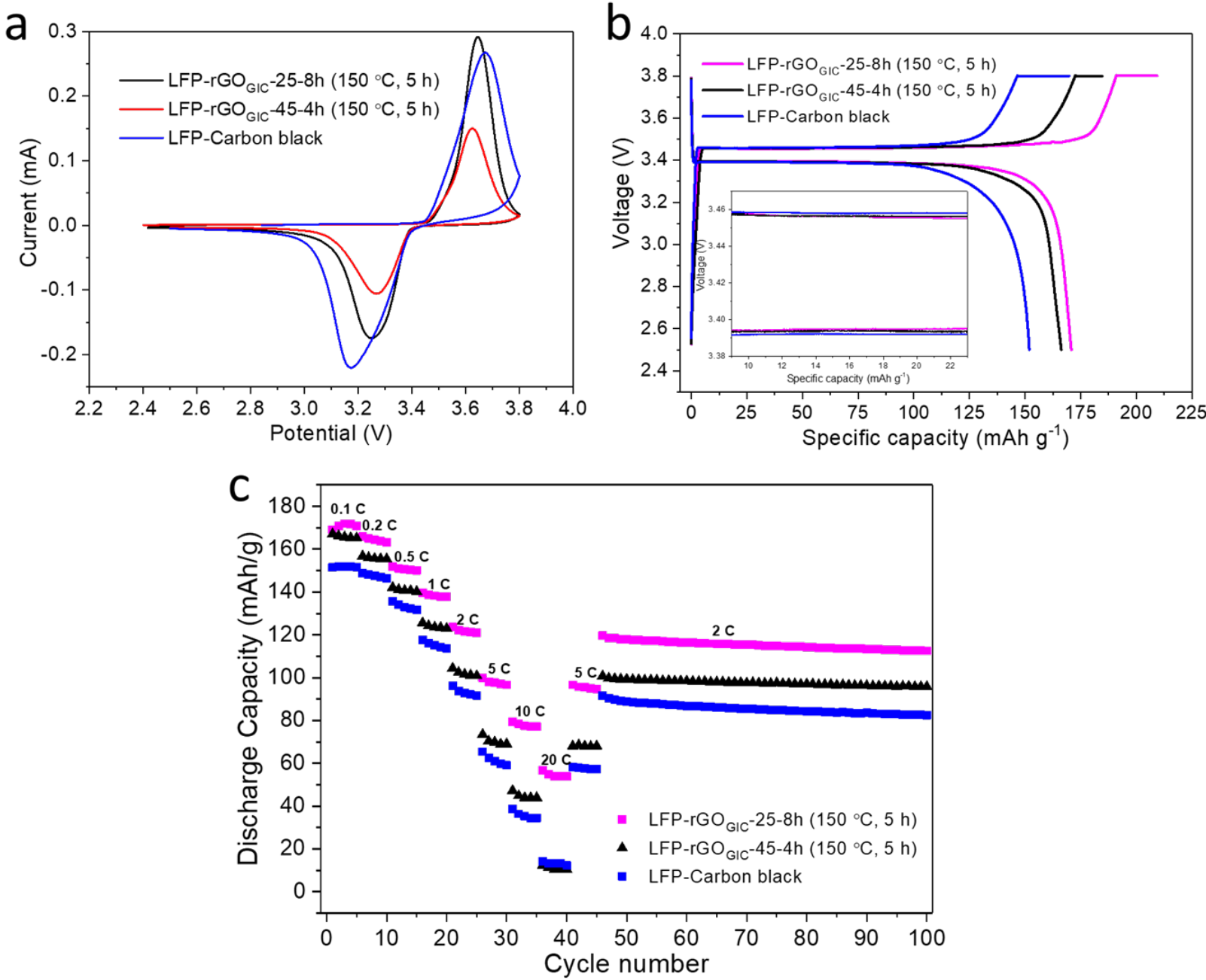

Figure 6. Electrochemical performances for $\mathrm{rGO}_{\mathrm{GIC}}-25-8 \mathrm{~h}$ and $\mathrm{rGO}_{\mathrm{GIC}}-45-4 \mathrm{~h}$ modified LFP cathodes in LIBs. The LIB's cathode with only carbon black as conductive additive served as a control. (a) Cyclic voltammetry for GO modified LIBs and the control at a scan rate of $0.1 \mathrm{mV} \mathrm{s}^{-1}$. (b) The voltage profiles for the second charge/discharge cycle at $0.1 \mathrm{C}$. Inset is a magnification of the 9-23 $\mathrm{mAh} \mathrm{g}^{-1}$ region. (c) Performance test for LIBs showing the discharge rate capacity at different rates and the cycling stability at $2 \mathrm{C}\left(1 \mathrm{C}=170 \mathrm{~mA} \mathrm{~g}^{-1}\right)$.

all $\mathrm{GO}_{\mathrm{GIC}}$ samples, due to the formation of $\pi$ conjugation in graphene. ${ }^{55}$

\section{Application of $\mathrm{GO}_{\mathrm{GIC}}$ and mild annealing condition for LIBs}

Because of its facile thermal recovery of conductivity, we employed the $\mathrm{GO}_{\mathrm{GIC}}$ as a $2 \mathrm{D}$ binder and conductive (after thermal annealing) additive in $\mathrm{LiFePO}_{4}$ (LFP) cathodes for LIBs. Carbon black was used as a control conductive additive. In the experimental condition, $50 \%$ of the carbon black was replaced with either $\mathrm{GO}_{\mathrm{GIC}}-25-8 \mathrm{~h}$ or $\mathrm{GO}_{\mathrm{GIC}}-45-$ $4 \mathrm{~h}$. As aforementioned, the residual weights of $\mathrm{GO}_{\mathrm{GIC}}-25-8 \mathrm{~h}$ and $\mathrm{GO}_{\mathrm{GIC}}-45-4 \mathrm{~h}$ stabilized after $5 \mathrm{~h}$ of thermal treatment at $150{ }^{\circ} \mathrm{C}$, as shown in Figure $4 \mathrm{~d}$. As such, the blended cathode materials were annealed at $150{ }^{\circ} \mathrm{C}$ in air for $5 \mathrm{~h}$ prior to the assembly of LIB coincells. SEM images (Figure S6) showed the LFP particles were homogeneously wrapped by GO sheets, which facilitated the formation of a conducting network after mild thermal annealing. As shown in Figure 6a, cyclic voltammetry (CV) for the control and the two experimental cathodes displayed a pair of redox peaks during the anodic/cathodic scan, associated with the reversible $\mathrm{Fe}^{2+} / \mathrm{Fe}^{3+}$ redox reaction in LFP cathodes. LFP-carbon black had greater separation between the two redox peaks than rGO modified LFP, indicating $\mathrm{rGO}$ assisted in reducing polarization and improving the reversibility of LFP cathodes. The charge/discharge profiles in Figure 6b exhibited a voltage plateau at $\sim 3.42 \mathrm{~V}$ vs. $\mathrm{Li}^{+} / \mathrm{Li}$ for all LIBs samples, also correlated with the redox reaction in LFP. Apparently, LFP-rGO ${ }_{\text {GIC }}-25-8 \mathrm{~h}$ can reach the highest discharge capacity up to $170.8 \mathrm{mAh} \mathrm{g}^{-1}$ at $0.1 \mathrm{C}$ rate. This value is similar to the theoretical specific capacity of LFP (170 mAh g-1) which is likely contributed by the reversible redox reaction between $\mathrm{Li}^{+}$of the electrolyte and rGO. ${ }^{39}$ Besides, the wider gap between discharge and charge plateaus in LFP-carbon black (inset in Figure $6 \mathbf{b}$ ) indicated its higher

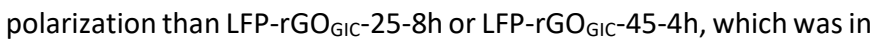
good agreement with the $\mathrm{CV}$ result. According to Figure $6 \mathrm{c}$, all LIBs showed good reversibility in discharge capacity as the current rate returned to $5 \mathrm{C}$ and $10 \mathrm{C}$. It also clearly showed the addition of $\mathrm{GO}$ can enhance the specific capacity at different discharge rate (except the highest rate $20 \mathrm{C}$ for LIB with $\mathrm{rGO}_{\mathrm{GIC}}-45-4 \mathrm{~h}$ ) relative to LIB without GO additives (carbon black only), and improve the cycle life due to 
less decay in discharge capacity of LIBs with $\mathrm{GO}$ after 55 cycles at $2 \mathrm{C}$ rate (Table S4). For $\mathrm{rGO}_{\mathrm{GIC}}-25-8 \mathrm{~h}$ modified LFP, it consistently exhibited better rate capability than LFP-rGOGIC-45-4h at all discharging rates, particularly the high rates (10 and $20 \mathrm{C}$ ). This is attributed to the better conductivity of $\mathrm{rGO}_{\mathrm{GIC}}-25-8 \mathrm{~h}$. As demonstrated by XPS, $\mathrm{rGO}_{\mathrm{GIC}}-25-8 \mathrm{~h}$ had more $\mathrm{sp}^{2}$ carbon which can provide a more conductive pathway for electron transport to the rGO modified LFP particles, thereby facilitating the $\mathrm{Li}^{+}$insertion and extraction process. ${ }^{56}$ Furthermore, LIBs with $\mathrm{rGO}_{\mathrm{GIC}}-25-8 \mathrm{~h}$ had comparable or even better battery performance relative to previous works which adopted rGO modified LFP (Table S4). It is noteworthy that the LFP particles employed in this work do not have any carbon coating and the entire LFP cathode fabrication process does not require any high temperature treatment (typically at $700{ }^{\circ} \mathrm{C}$ under inert atmosphere).

\section{Conclusions}

In conclusion, we have presented a simple modified Hummers method to prepare well-oxidized but less defective GO using expandable graphite as the starting material. Compared to natural graphite with the similar flake size, the oxidation of expandable graphite was easier and, more importantly, can be carried out at room temperature. The GO synthesized at room temperature has lesser carbonyl and carboxylic acid groups and most of its thermally labile oxygen groups (C-O) could be removed, with restoration of conductive $\mathrm{sp}^{2}$ carbon, at a mild annealing temperature of $150^{\circ} \mathrm{C}$. Finally, we directly employed the GO in our LIB cathode formulation, which contributed as a 2D binder, and followed by the mild annealing process to afford a superior graphene-wrapped LFP cathode with improved capacity as well as rate performance. The mild but effective thermal reductive deoxygenation of this type of GO opens up the possibility of a more facile, energy saving and greener approach to preparing a variety of electroconductive applications for graphene materials.

\section{Conflicts of interest}

There are no conflicts to declare.

\section{Acknowledgements}

This work was financially supported by the Australian Research Council (LP160101521 and DP170104157).

\section{Notes and references}

1. S. Wu, R. Xu, M. Lu, R. Ge, J. locozzia, C. Han, B. Jiang and Z. Lin, Advanced Energy Materials, 2015, 5, 1500400.

2. Y. Jia, L. Zhang, A. Du, G. Gao, J. Chen, X. Yan, C. L. Brown and X. Yao, Adv. Mater., 2016, 28, 9532-9538.

3. G. Shi, Z. Zhao, J.-H. Pai, I. Lee, L. Zhang, C. Stevenson, K. Ishara, R. Zhang, H. Zhu and J. Ma, Adv. Funct. Mater., 2016, 26, 7614-7625.

4. Y. L. Zhong, Z. Tian, G. P. Simon and D. Li, Mater. Today, 2015, 18, 73-78.
D. R. Dreyer, S. Park, C. W. Bielawski and R. S. Ruoff, Chem. Soc. Rev., 2010, 39, 228-240.

Y. Zhu, S. Murali, W. Cai, X. Li, J. W. Suk, J. R. Potts and R. S. Ruoff, Adv. Mater., 2010, 22, 3906-3924.

V. C. Tung, M. J. Allen, Y. Yang and R. B. Kaner, Nature Nanotechnology, 2008, 4, 25.

E. M. Milner, N. T. Skipper, C. A. Howard, M. S. P. Shaffer, D. J. Buckley, K. A. Rahnejat, P. L. Cullen, R. K. Heenan, P. Lindner and R. Schweins, J. Am. Chem. Soc., 2012, 134, 8302-8305.

D. Li, M. B. Muller, S. Gilje, R. B. Kaner and G. G. Wallace, Nat Nano, 2008, 3, 101-105.

J. Chen, Y. Li, L. Huang, C. Li and G. Shi, Carbon, 2015, 81 , 826-834.

N. Behabtu, J. R. Lomeda, M. J. Green, A. L. Higginbotham A. Sinitskii, D. V. Kosynkin, D. Tsentalovich, A. N. G. ParraVasquez, J. Schmidt, E. Kesselman, Y. Cohen, Y. Talmon, J. M. Tour and M. Pasquali, Nat Nano, 2010, 5, 406-411.

S. Stankovich, R. D. Piner, X. Chen, N. Wu, S. T. Nguyen and R. S. Ruoff, Journal of Materials Chemistry, 2006, 16, 155158.

I. Jung, M. Pelton, R. Piner, D. A. Dikin, S. Stankovich, S. Watcharotone, M. Hausner and R. S. Ruoff, Nano Letters, 2007, 7, 3569-3575.

W. S. Hummers and R. E. Offeman, J. Am. Chem. Soc., 1958, 80, 1339-1339.

D. C. Marcano, D. V. Kosynkin, J. M. Berlin, A. Sinitskii, Z. Sun, A. Slesarev, L. B. Alemany, W. Lu and J. M. Tour, ACS Nano, 2010, 4, 4806-4814.

S. Eigler, C. Dotzer and A. Hirsch, Carbon, 2012, 50, 3666 3673.

L. R. Radovic, J. Am. Chem. Soc., 2009, 131, 17166-17175. S. Pan and I. A. Aksay, ACS Nano, 2011, 5, 4073-4083.

M. J. McAllister, J.-L. Li, D. H. Adamson, H. C. Schniepp, A. A. Abdala, J. Liu, M. Herrera-Alonso, D. L. Milius, R. Car, R. K. Prud'homme and I. A. Aksay, Chemistry of Materials, 2007, 19, 4396-4404.

A. M. Dimiev and J. M. Tour, ACS Nano, 2014, 8, 3060-3068. L. Dong, J. Yang, M. Chhowalla and K. P. Loh, Chem. Soc. Rev., 2017, 46, 7306-7316.

N. I. Kovtyukhova, P. J. Ollivier, B. R. Martin, T. E. Mallouk, S. A. Chizhik, E. V. Buzaneva and A. D. Gorchinskiy, Chem. Mater., 1999, 11, 771-778.

Y. Xu, H. Bai, G. Lu, C. Li and G. Shi, J. Am. Chem. Soc., 2008, 130, 5856-5857.

Z. Luo, Y. Lu, L. A. Somers and A. T. C. Johnson, J. Am. Chem. Soc., 2009, 131, 898-899.

S. H. Aboutalebi, M. M. Gudarzi, Q. B. Zheng and J.-K. Kim, Adv. Funct. Mater., 2011, 21, 2978-2988.

Q. Zheng, W. H. Ip, X. Lin, N. Yousefi, K. K. Yeung, Z. Li and J.-K. Kim, ACS Nano, 2011, 5, 6039-6051.

J. Jia, C.-M. Kan, X. Lin, X. Shen and J.-K. Kim, Carbon, 2014, 77, 244-254.

L. Dong, Z. Chen, S. Lin, K. Wang, C. Ma and H. Lu, Chemistry of Materials, 2017, 29, 564-572.

S. Eigler, M. Enzelberger-Heim, S. Grimm, P. Hofmann, W. Kroener, A. Geworski, C. Dotzer, M. Röckert, J. Xiao, C. Papp, O. Lytken, H.-P. Steinrück, P. Müller and A. Hirsch, Adv. Mater., 2013, 25, 3583-3587.

B. Butz, C. Dolle, C. E. Halbig, E. Spiecker and S. Eigler, Angewandte Chemie International Edition, 2016, 55, 15771-15774. 
31. J. Chen, Y. Zhang, M. Zhang, B. Yao, Y. Li, L. Huang, C. Li and G. Shi, Chemical Science, 2016, 7, 1874-1881.

32. H. Chen, W. Du, J. Liu, L. Qu and C. Li, Chemical Science, 2019, 10, 1244-1253.

33. X. Zhu, Y. Zhu, S. Murali, M. D. Stoller and R. S. Ruoff, ACS Nano, 2011, 5, 3333-3338.

34. X. Yang, L. Qiu, C. Cheng, Y. Wu, Z.-F. Ma and D. Li, Angew. Chem. Int. Ed., 2011, 50, 7325-7328.

35. I. K. Moon, J. Lee, R. S. Ruoff and H. Lee, Nature Communications, 2010, 1, 73.

36. X. Zhu, J. Hu, W. Wu, W. Zeng, H. Dai, Y. Du, Z. Liu, L. Li, H. $\mathrm{Ji}$ and Y. Zhu, Journal of Materials Chemistry A, 2014, 2, 7812-7818.

37. Y. Zhu, M. D. Stoller, W. Cai, A. Velamakanni, R. D. Piner, D. Chen and R. S. Ruoff, ACS Nano, 2010, 4, 1227-1233.

38. Y. Huang, H. Liu, Y.-C. Lu, Y. Hou and Q. Li, J. Power Sources, 2015, 284, 236-244.

39. B. Lung-Hao Hu, F.-Y. Wu, C.-T. Lin, A. N. Khlobystov and L.J. Li, Nature Communications, 2013, 4, 1687.

40. J. Chen, B. Yao, C. Li and G. Shi, Carbon, 2013, 64, 225-229.

41. J. Shen, Y. Hu, M. Shi, X. Lu, C. Qin, C. Li and M. Ye, Chem. Mater., 2009, 21, 3514-3520.

42. S. Park, J. An, J. R. Potts, A. Velamakanni, S. Murali and R. S. Ruoff, Carbon, 2011, 49, 3019-3023.

43. P. Yu, S. E. Lowe, G. P. Simon and Y. L. Zhong, Current Opinion in Colloid \& Interface Science, 2015, 20, 329-338.

44. N. E. Sorokina, M. A. Khaskov, V. V. Avdeev and I. V. Nikol'skaya, Russ. J. Gen. Chem., 2005, 75, 162-168.

45. M. Salvatore, G. Carotenuto, S. De Nicola, C. Camerlingo, V. Ambrogi and C. Carfagna, Nanoscale Research Letters, 2017, 12, 167.

46. G. Shi, A. Michelmore, J. Jin, L. H. Li, Y. Chen, L. Wang, H. Yu, G. Wallace, S. Gambhir, S. Zhu, P. Hojati-Talemi and J. Ma, Journal of Materials Chemistry A, 2014, 2, 2038220392.

47. M. Cai, D. Thorpe, D. H. Adamson and H. C. Schniepp, Journal of Materials Chemistry, 2012, 22, 24992-25002.

48. Y. Wen, M. Wu, M. Zhang, C. Li and G. Shi, Advanced Materials, 2017, 29, 1702831.

49. A. C. Ferrari, J. C. Meyer, V. Scardaci, C. Casiraghi, M. Lazzeri, F. Mauri, S. Piscanec, D. Jiang, K. S. Novoselov, S. Roth and A. K. Geim, Phys. Rev. Lett., 2006, 97, 187401.

50. A. C. Ferrari and J. Robertson, Physical Review B, 2000, 61, 14095-14107.

51. S. Eigler, C. Dotzer, A. Hirsch, M. Enzelberger and P. Müller, Chem. Mater., 2012, 24, 1276-1282.

52. S. E. Lowe, G. Shi, Y. Zhang, J. Qin, S. Wang, A. Uijtendaal, J. Sun, L. Jiang, S. Jiang, D. Qi, M. Al-Mamun, P. Liu, Y. L. Zhong and H. Zhao, ACS Applied Nano Materials, 2019, 2, 867-878.

53. C. Mattevi, G. Eda, S. Agnoli, S. Miller, K. A. Mkhoyan, O. Celik, D. Mastrogiovanni, G. Granozzi, E. Garfunkel and M. Chhowalla, Advanced Functional Materials, 2009, 19, 2577-2583.

54. A. Dimiev, D. V. Kosynkin, L. B. Alemany, P. Chaguine and J. M. Tour, J. Am. Chem. Soc., 2012, 134, 2815-2822.

55. C.-C. Teng, C.-C. M. Ma, C.-H. Lu, S.-Y. Yang, S.-H. Lee, M.C. Hsiao, M.-Y. Yen, K.-C. Chiou and T.-M. Lee, Carbon, 2011, 49, 5107-5116.

56. C. M. Julien, K. Zaghib, A. Mauger, M. Massot, A. Ait-Salah, M. Selmane and F. Gendron, Journal of Applied Physics, 2006, 100, 063511. 


\section{Room Temperature Production of Graphene Oxide with Thermally-labile Oxygen Functional Groups for Improved Lithium Ion Batteries Fabrication and Performance}

Jiadong Qin§, Yubai Zhang ${ }^{\S}$, Sean E. Lowe, Lixue Jiang, Han Yeu Ling, Ge Shi, Porun Liu, Shanqing Zhang, Yu Lin Zhong*, Huijun Zhao*

Centre for Clean Environment and Energy, School of Environment and Science, Griffith University Gold Coast Campus, Queensland 4222, Australia.

*Corresponding author: y.zhong@griffith.edu.au, h.zhao@griffith.edu.au

$\S$ These authors contribute equally to this work. 


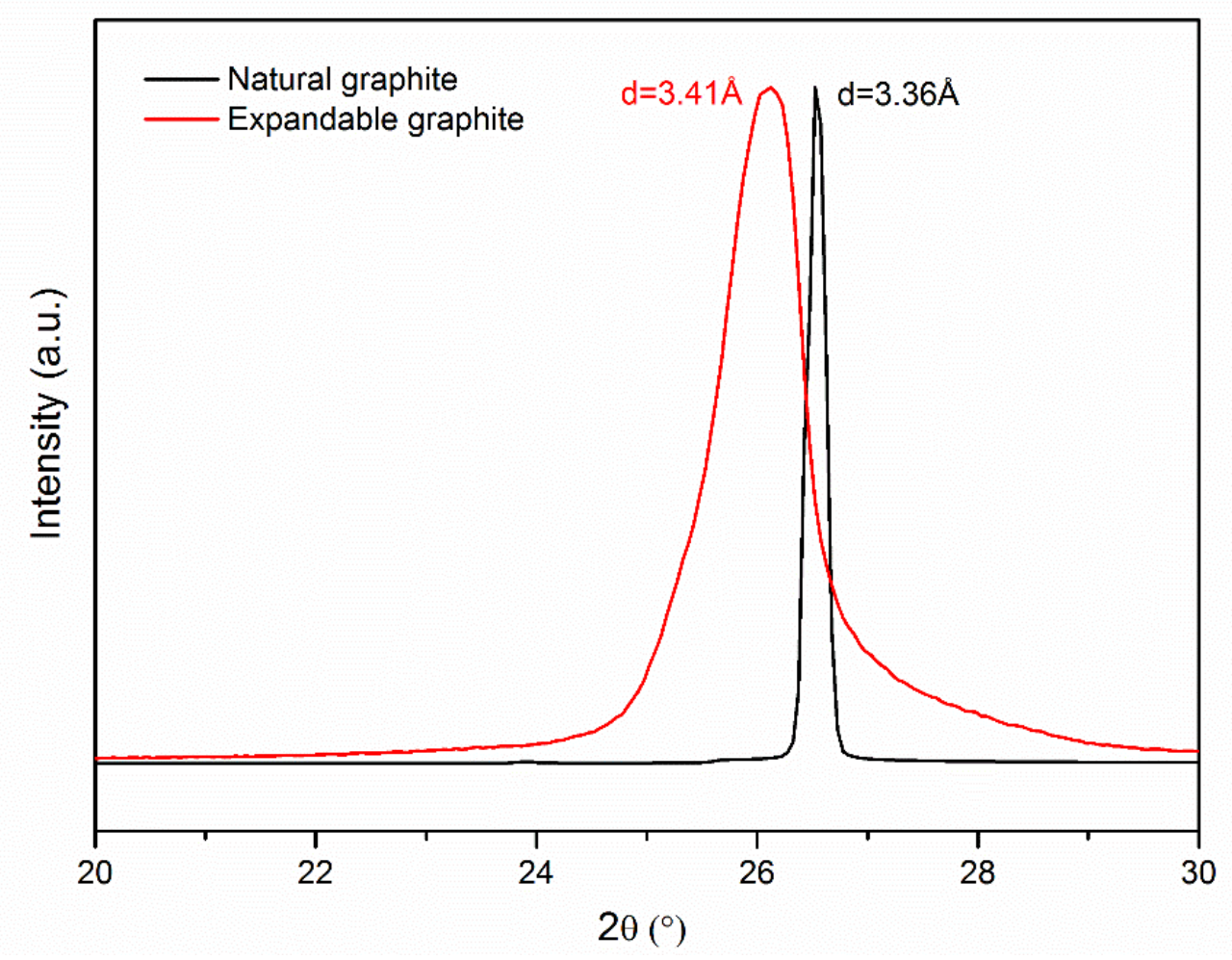

Figure S1. The XRD curves for expandable graphite and natural graphite.

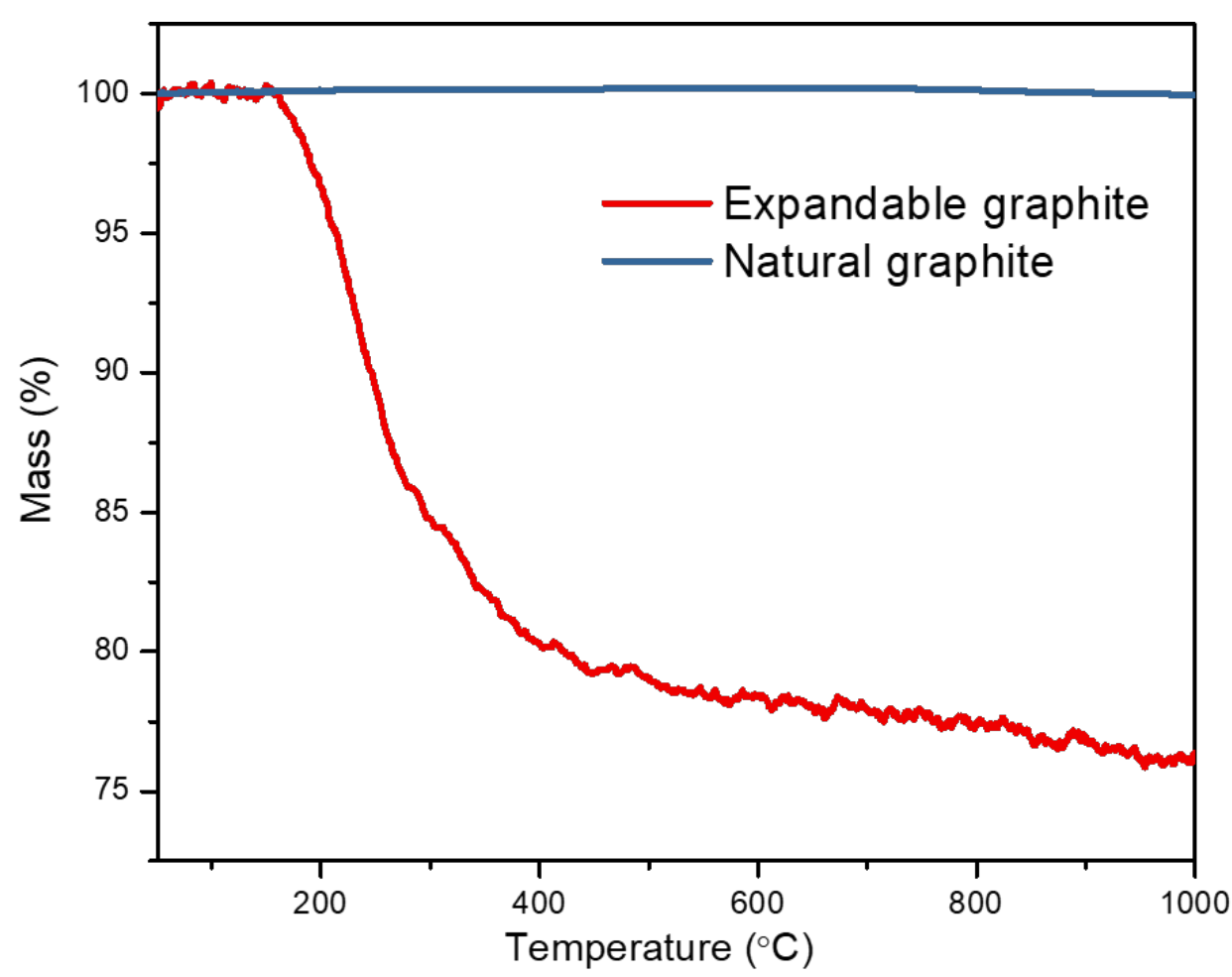

Figure S2. TGA curves of expandable graphite and natural graphite heated from 50 to $1000^{\circ} \mathrm{C}$ at the rate of $5 \mathrm{~K} / \mathrm{min}$ under pure argon atmosphere. 

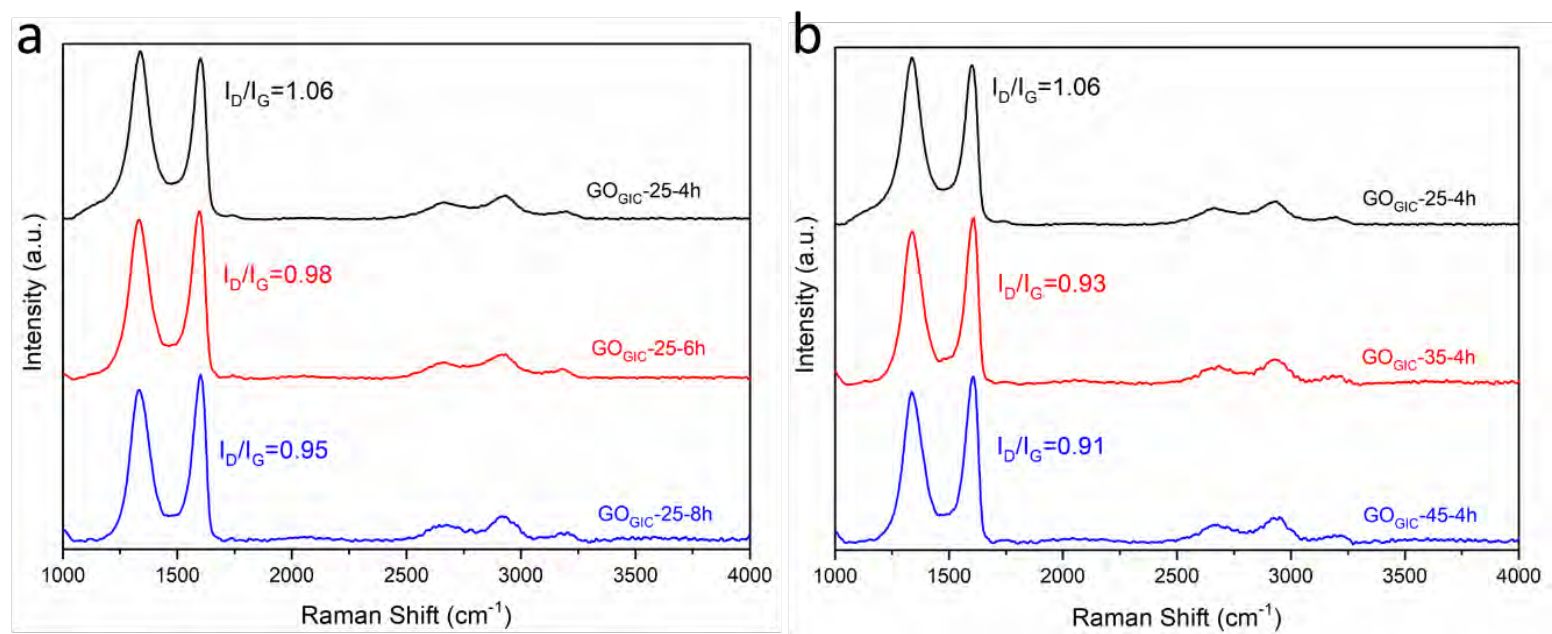

Figure S3. The Raman spectra of $\mathrm{GO}_{\mathrm{GIC}}(\mathrm{a})$ at the temperature of $25^{\circ} \mathrm{C}$ for different time, and (b) at different temperature for $4 \mathrm{~h}$.
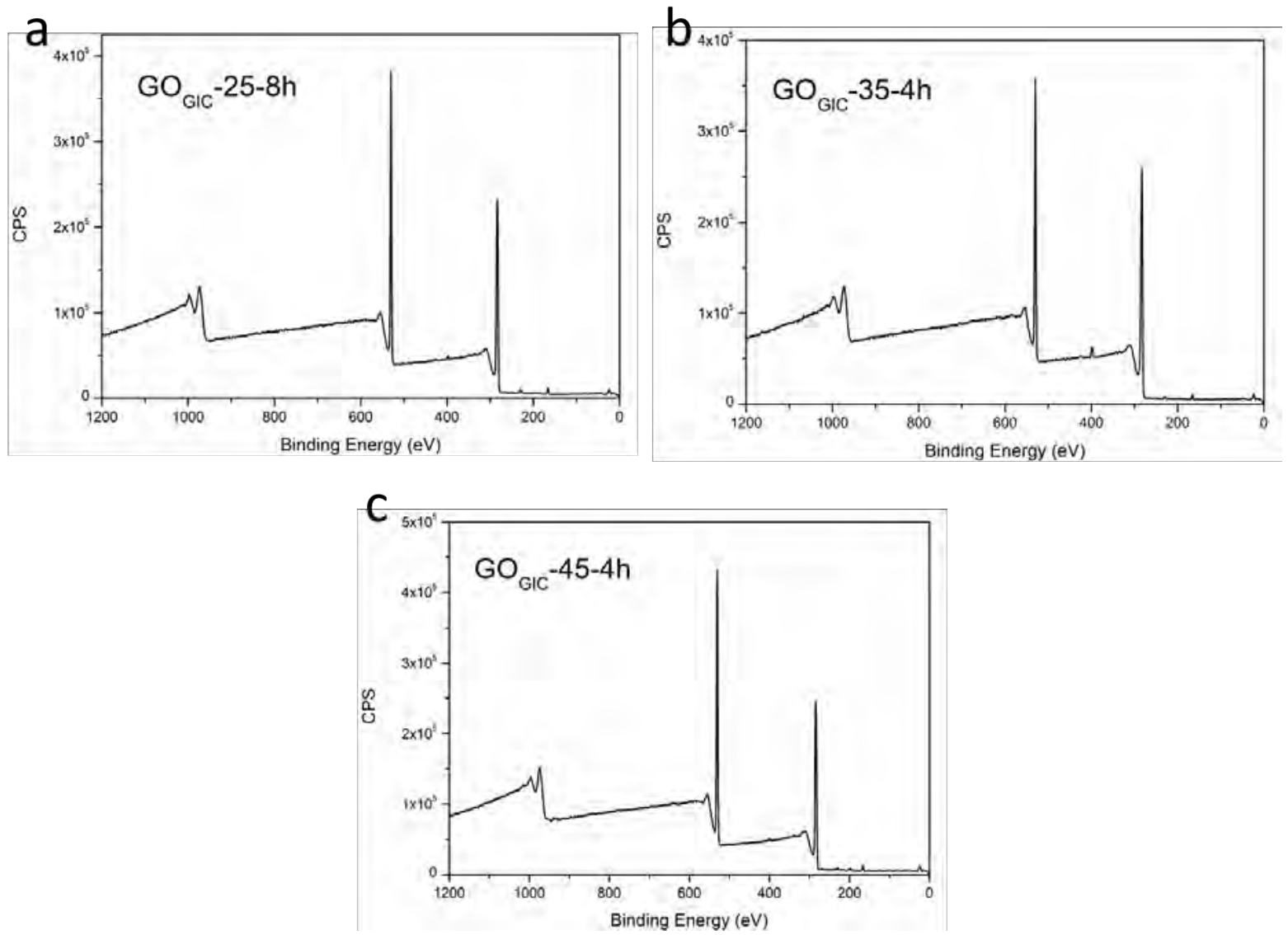

Figure S4. XPS survey spectra for different $\mathrm{GO}_{\mathrm{GIC}}$ samples. The $\mathrm{C} / \mathrm{O}$ ratios for $\mathrm{GO}_{\mathrm{GIC}}-25-8 \mathrm{~h}$, $\mathrm{GO}_{\mathrm{GIC}}-35-4 \mathrm{~h}$ and $\mathrm{GO}_{\mathrm{GIC}}-45-4 \mathrm{~h}$ were $2.68,3.05$ and 2.41 , respectively. 


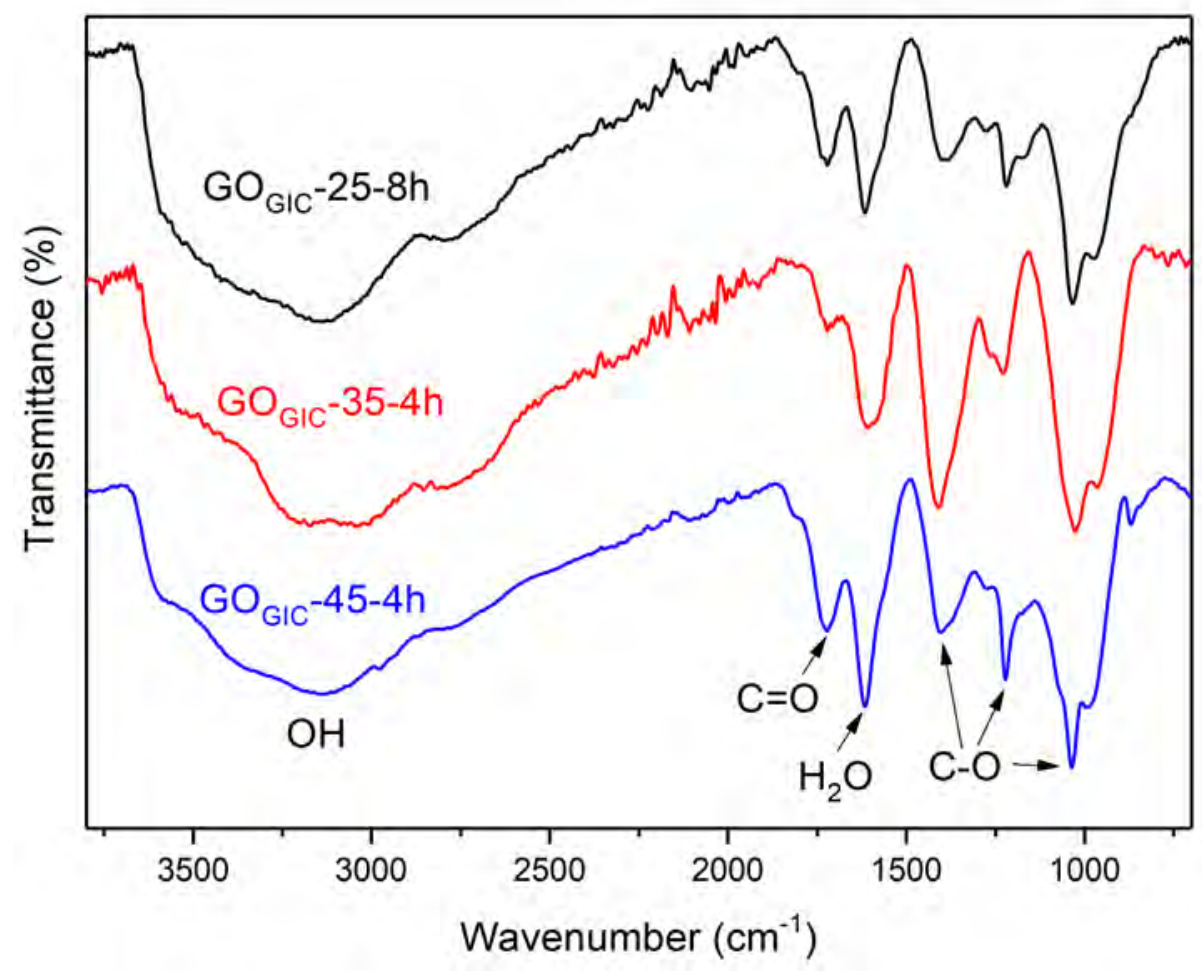

Figure S5. ATR-FTIR spectra for $\mathrm{GO}_{\mathrm{GIC}}$ films which indicated the presence of $\mathrm{C}=\mathrm{O}$ (the peak at $\sim 1723 \mathrm{~cm}^{-1}$ ), C-O (at 1400 and $1225 \mathrm{~cm}^{-1}$ ) and $-\mathrm{OH}\left(3700-2700 \mathrm{~cm}^{-1}\right)$ in GO samples. ${ }^{1,2}$
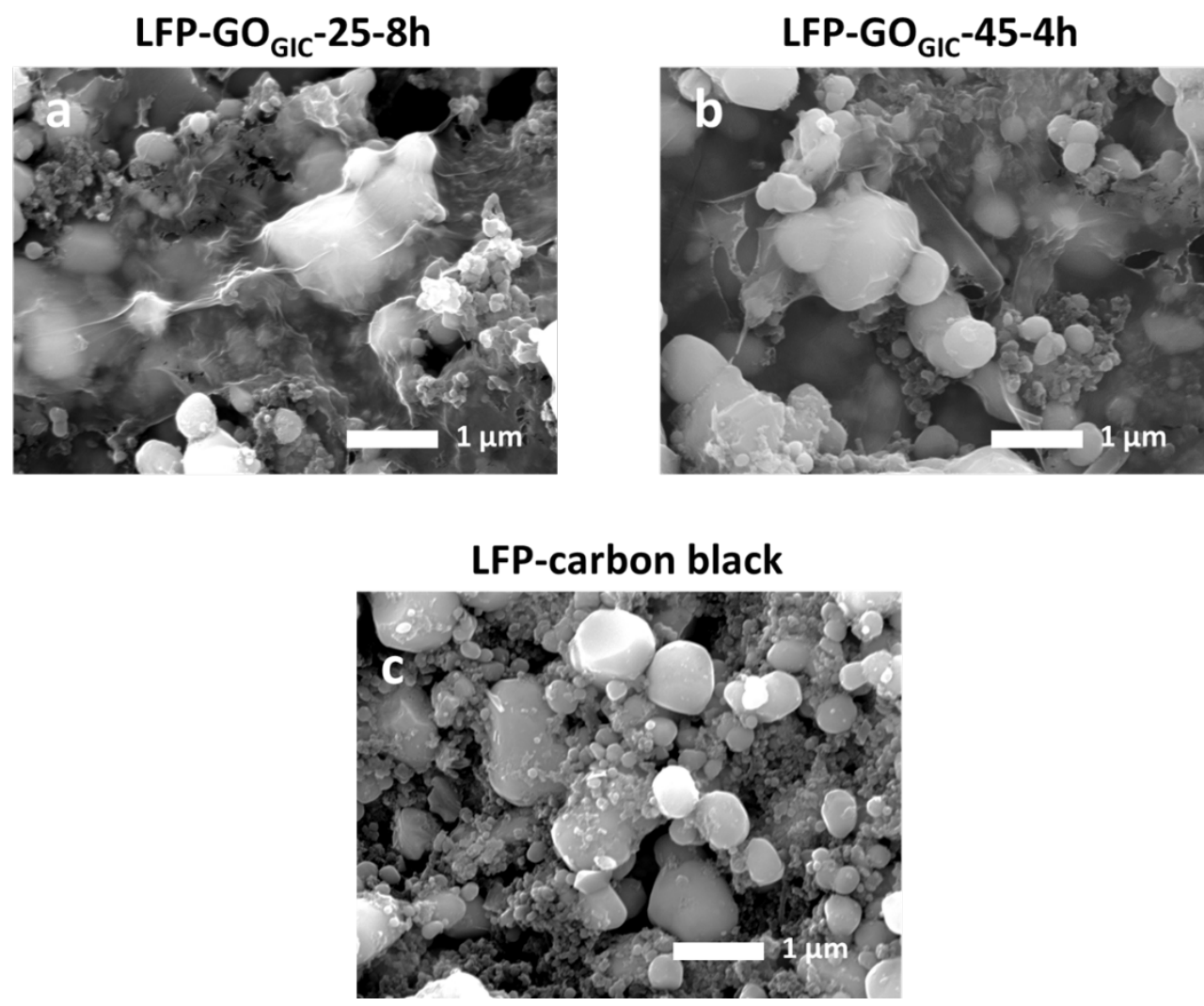

Figure S6. SEM images for $\mathrm{GO}_{\mathrm{GIC}}$ modified LFP cathodes and unmodified LFP cathode. 
Table S1. The residual weight percentage of $\mathrm{GO}_{\mathrm{GIC}}$ after $6 \mathrm{~h}$ of thermal treatment at 150, 175 and $200{ }^{\circ} \mathrm{C}$ in $20 \% \mathrm{O}_{2} / 80 \% \mathrm{Ar}$ atmosphere.

\begin{tabular}{llll}
\hline Annealing temperature & $150{ }^{\circ} \mathrm{C}$ & $175{ }^{\circ} \mathrm{C}$ & $200{ }^{\circ} \mathrm{C}$ \\
\hline $\mathrm{GO}_{\mathrm{GIC}-25-8 \mathrm{~h}}$ & $69 \%$ & $66 \%$ & $65 \%$ \\
$\mathrm{GO}_{\mathrm{GIC}-35-4 \mathrm{~h}}$ & $77 \%$ & $73 \%$ & $70 \%$ \\
$\mathrm{GO}_{\mathrm{GIC}-45-4 \mathrm{~h}}$ & $72 \%$ & $65 \%$ & $61 \%$ \\
\hline
\end{tabular}

Table S2. The atomic percentages of five components in the unreduced $\mathrm{GO}_{\mathrm{GIC}}$ according to the fitted C1s XPS curves in Figure 4g-i.

\begin{tabular}{llll}
\hline & $\mathbf{G O}_{\mathrm{GIC}-\mathbf{2 5 - 8 h}}$ & $\mathbf{G O}_{\mathrm{GIC}-\mathbf{3 5}-\mathbf{4 h}}$ & $\mathbf{G O}_{\mathrm{GIC}-\mathbf{4 5}-\mathbf{4 h}}$ \\
\hline $\mathrm{C}=\mathrm{C} / \mathrm{C}-\mathrm{C}$ & $48.18 \%$ & $56.53 \%$ & $44.79 \%$ \\
$\mathbf{C}-\mathbf{0}$ & $44.43 \%$ & $35.44 \%$ & $45.61 \%$ \\
$\mathrm{C}=\mathbf{0}$ & $5.04 \%$ & $4.81 \%$ & $6.04 \%$ \\
$\mathrm{COOH}$ & $2.29 \%$ & $2.81 \%$ & $3.49 \%$ \\
$\pi-\pi^{*}$ & $0.05 \%$ & $0.41 \%$ & $0.07 \%$ \\
\hline
\end{tabular}

Table S3. The atomic percentages of five components in the reduced $\mathrm{GO}_{\mathrm{GIC}}$ after $5 \mathrm{~h}$ of $150{ }^{\circ} \mathrm{C}$ thermal annealing according to the fitted C1s XPS curves in Figure 4j-I.

\begin{tabular}{llll}
\hline & $\begin{array}{l}\mathrm{rGO}_{\mathrm{GIC}-\mathbf{2 5}-\mathbf{8 h}} \\
\left(\mathbf{1 5 0}{ }^{\circ} \mathbf{C}, \mathbf{5 h}\right)\end{array}$ & $\begin{array}{l}\mathrm{rGO}_{\mathrm{GIC}-35-4 h} \\
\left(\mathbf{1 5 0}{ }^{\circ} \mathrm{C}, \mathbf{5 h}\right)\end{array}$ & $\begin{array}{l}\mathrm{rGO}_{\mathrm{GIC}}-\mathbf{4 5}-\mathbf{4 h} \\
\left(\mathbf{1 5 0}{ }^{\circ} \mathrm{C}, \mathbf{5 h}\right)\end{array}$ \\
\hline $\mathrm{C}=\mathrm{C} / \mathrm{C}-\mathrm{C}$ & $72.56 \%$ & $66.44 \%$ & $63.83 \%$ \\
$\mathrm{C}-\mathrm{O}$ & $15.01 \%$ & $20.00 \%$ & $19.37 \%$ \\
$\mathrm{C}=0$ & $5.93 \%$ & $6.21 \%$ & $9.10 \%$ \\
$\mathrm{COOH}$ & $4.34 \%$ & $4.51 \%$ & $4.95 \%$ \\
$\pi-\pi^{*}$ & $2.16 \%$ & $2.84 \%$ & $1.97 \%$ \\
\hline
\end{tabular}


Table S4. Summary of various $\mathrm{rGO}$ modified $\mathrm{LiFePO}_{4}$ cathodes. In the case of pre-reduced $\mathrm{GO}, \mathrm{GO}$ was reduced first and then mixed with other active materials for the assembly of LIBS.

\begin{tabular}{|c|c|c|c|c|c|}
\hline $\begin{array}{l}\text { Surface } \\
\text { treatment on } \\
\text { LFP particles }\end{array}$ & Conductive additives & $\begin{array}{l}\text { Specific } \\
\text { Capacity at } \\
0.1 \mathrm{C} \text { rate } \\
\left(\mathrm{mA} \cdot \mathrm{h} \cdot \mathrm{g}^{-1}\right)\end{array}$ & $\begin{array}{l}\text { High rate } \\
\text { performanc } \\
\text { e }\left(\mathrm{mA} \cdot \mathrm{h} \cdot \mathrm{g}^{-1}\right)\end{array}$ & $\begin{array}{l}\text { Capacity } \\
\text { Fading Per } \\
\text { Cycle (\%) }\end{array}$ & Ref. \\
\hline No & $\mathrm{rGO}_{\mathrm{GIC}}-25-8 \mathrm{~h}$ & 171 (at $0.1 \mathrm{C}$ ) & $\begin{array}{l}77(\text { at } 10 \mathrm{C}) \\
54(\text { at } 20 \mathrm{C})\end{array}$ & $\begin{array}{l}-0.11(55 \\
\text { cycles at } 2 \mathrm{C})\end{array}$ & $\begin{array}{l}\text { This } \\
\text { work }\end{array}$ \\
\hline No & $\mathrm{rGO}_{\mathrm{GIC}}-45-4 \mathrm{~h}$ & 166 (at $0.1 \mathrm{C}$ ) & $\begin{array}{l}45 \text { (at } 10 \mathrm{C} \text { ) } \\
11 \text { (at } 20 \mathrm{C} \text { ) }\end{array}$ & $\begin{array}{c}-0.09(55 \\
\text { cycles at } 2 \mathrm{C})\end{array}$ & $\begin{array}{l}\text { This } \\
\text { work }\end{array}$ \\
\hline No & No rGO, carbon black only & 152 (at $0.1 \mathrm{C}$ ) & $\begin{array}{l}36 \text { (at } 10 \mathrm{C} \text { ) } \\
13 \text { (at } 20 \mathrm{C} \text { ) }\end{array}$ & $\begin{array}{c}-0.18 \text { (55 } \\
\text { cycles at } 2 \mathrm{C} \text { ) }\end{array}$ & $\begin{array}{l}\text { This } \\
\text { work }\end{array}$ \\
\hline No & $\begin{array}{l}\text { Electrophoretic deposition of GO and } \\
\text { LFP particles on carbon cloth } \\
\text { followed by annealing at } 700^{\circ} \mathrm{C}\end{array}$ & 174.7 & 90 (at $10 \mathrm{C}$ ) & $\begin{array}{l}-0.0027(400 \\
\text { cycles at } 2 \mathrm{C})\end{array}$ & [3] \\
\hline No & $\begin{array}{l}\text { Pre-reduced GO (reduced by } \\
\text { hydrazine) }\end{array}$ & Not provided & $\begin{array}{l}87(\text { at } 10 \mathrm{C}) \\
69(\text { at } 20 \mathrm{C})\end{array}$ & Not provided & [4] \\
\hline APS-modified LFP & $\begin{array}{l}\text { Reduced GO (co-heated with LFP at } \\
\qquad 600^{\circ} \mathrm{C} \text { under } \mathrm{Ar} / \mathrm{H}_{2} \text { ) }\end{array}$ & Not provided & $\begin{array}{l}105 \text { (at } 10 \mathrm{C}) \\
70(\text { at } 20 \mathrm{C})\end{array}$ & $\begin{array}{l}-0.009(950 \\
\text { cycles at } 10 \mathrm{C})\end{array}$ & [5] \\
\hline $\begin{array}{l}\text { Carbon coated } \\
\text { LFP }\end{array}$ & $\begin{array}{c}\text { Pre-reduced GO (reduced by } \\
\text { hydrazine and annealed under } \mathrm{N}_{2} / \mathrm{H}_{2} \text { ) }\end{array}$ & 152 & 107 (at $10 \mathrm{C}$ ) & $\begin{array}{c}0.167(100 \\
\text { cycles at } 0.1 \mathrm{C})\end{array}$ & [6] \\
\hline $\begin{array}{l}\text { Hydrothermal } \\
\text { synthesized } \\
\text { LFP/rGO hybrids }\end{array}$ & rGO (co-heated with LFP at $700^{\circ} \mathrm{C}$ ) & 166 & $\begin{array}{l}75(\text { at } 10 \mathrm{C}) \\
60(\text { at } 15 \mathrm{C})\end{array}$ & $\begin{array}{c}-0.013(100 \\
\text { cycles at } 0.1 \mathrm{C})\end{array}$ & [7] \\
\hline
\end{tabular}

\section{References}

1. A. M. Dimiev, L. B. Alemany and J. M. Tour, ACS Nano, 2013, 7, 576-588.

2. D. C. Marcano, D. V. Kosynkin, J. M. Berlin, A. Sinitskii, Z. Sun, A. Slesarev, L. B. Alemany, W. Lu and J. M. Tour, ACS Nano, 2010, 4, 4806-4814.

3. Y. Huang, H. Liu, Y.-C. Lu, Y. Hou and Q. Li, J. Power Sources, 2015, 284, 236-244.

4. H. Bi, F. Huang, Y. Tang, Z. Liu, T. Lin, J. Chen and W. Zhao, Electrochimica Acta, 2013, 88, 414-420.

5. W.-B. Luo, S.-L. Chou, Y.-C. Zhai and H.-K. Liu, Journal of Materials Chemistry A, 2014, 2, 4927-4931.

6. M. Lin, Y. Chen, B. Chen, X. Wu, K. Kam, W. Lu, H. L. W. Chan and J. Yuan, ACS Applied Materials \& Interfaces, 2014, 6, 17556-17563.

7. J. Yang, J. Wang, Y. Tang, D. Wang, X. Li, Y. Hu, R. Li, G. Liang, T.-K. Sham and X. Sun, Energy Environ. Sci., 2013, 6, 1521-1528. 